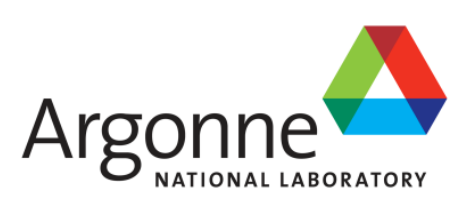

ANL/NE-15/9 Rev. 1

\title{
Supplement to the NUBOW-3D Manual
}

Nuclear Engineering Division 


\section{About Argonne National Laboratory}

Argonne is a U.S. Department of Energy laboratory managed by UChicago Argonne, LLC

under contract DE-AC02-06CH11357. The Laboratory's main facility is outside Chicago, at 9700 South Cass Avenue, Argonne, Illinois 60439. For information about Argonne

and its pioneering science and technology programs, see www.anl.gov.

\section{DOCUMENT AVAILABILITY}

Online Access: U.S. Department of Energy (DOE) reports produced after 1991 and a growing number of pre-1991 documents are available free at OSTI.GOV (http://www.osti.gov/), a service of the US Dept. of Energy's Office of Scientific and Technical Information.

\section{Reports not in digital format may be purchased by the public from the} National Technical Information Service (NTIS):

U.S. Department of Commerce

National Technical Information Service

5301 Shawnee Rd

Alexandria, VA 22312

www.ntis.gov

Phone: (800) 553-NTIS (6847) or (703) 605-6000

Fax: (703) 605-6900

Email:orders@ntis.gov

Reports not in digital format are available to DOE and DOE contractors from the Office of Scientific and Technical Information (OSTI):

U.S. Department of Energy

Office of Scientific and Technical Information

P.O. Box 62

Oak Ridge, TN 37831-0062

www.osti.gov

Phone: (865) 576-8401

Fax: (865) 576-5728

Email: reports@osti.gov 
ANL/NE-15/9 Rev. 1

Supplement to the NUBOW-3D Manual

J. J. Grudzinski, T. Moran, C. Grandy

Nuclear Engineering Division

Argonne National Laboratory

May 2015

updated May 8, 2017 



\section{ABSTRACT}

The NUBOW-3D code (NUBOW) developed in 1978 is a custom FORTRAN analysis code that models the complex mechanical interaction of the fuel assemblies and the core restraint system in response to the effects of thermal expansion and irradiation swelling and creep. NUBOW-3D models the fuel assembly ducts as beams with springs representing the contact between ducts. The core temperature profile and neutron flux profiles are provided at various times during the planned operation of the reactor. NUBOW then calculates the changing shapes of the fuel assemblies and their equilibrium positions within the core restraints. An optional post-processing step calculates the reactivity changes based on new positions of the fuel assemblies using input displacement reactivity WORTHS.

Understanding this reactivity change is a key feature to the inherent safety of a fast reactor core. NUBOW was developed to support the design of limited free bow core restraint systems.

The NUBOW software was modified in 1987 but the documentation of the upgrades was not completed due to abrupt funding cuts. In the last few years, the software has been ported to a Windows platform using a current FORTRAN compiler and additional changes have been made including consolidating the code to a single executable.

While the original NUBOW manual [1] written in 1978 provides an excellent description of the code and input parameters, it lacks the additional features added in the upgrades and in some cases describes features that are no longer operable. This report attempts to bridge the information gap between the original manual and the current state of the software. 


\section{Table of Contents}

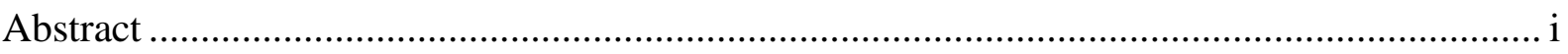

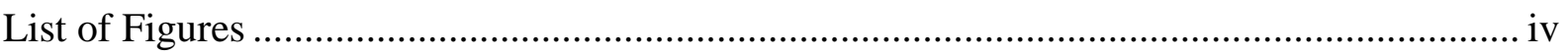

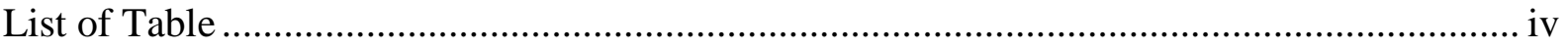

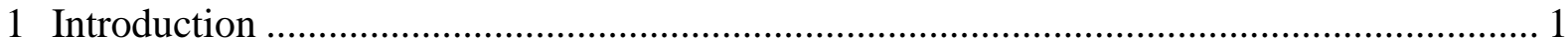

2 Program structure and file description........................................................................ 3

3 User Prepared Input files ……………...................................................................... 9

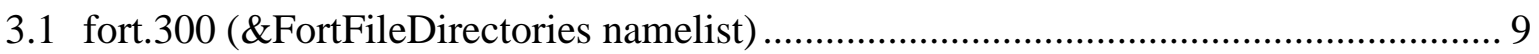

3.2 fort.1 (\&batchInput namelist)............................................................................. 10

3.3 fort.4 (\&INPUT namelist) ............................................................................... 11

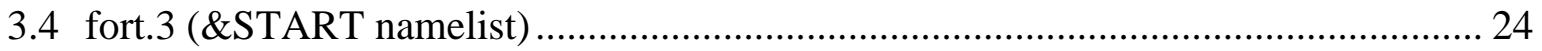

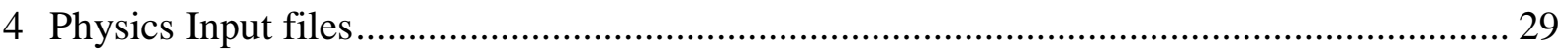

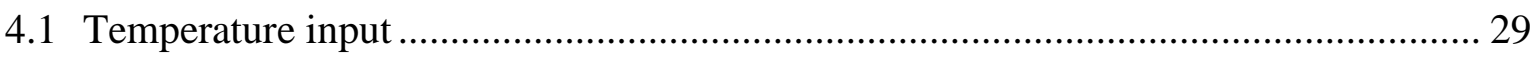

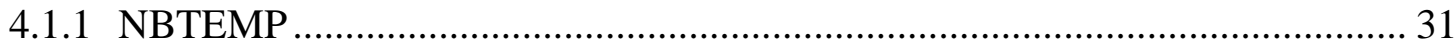

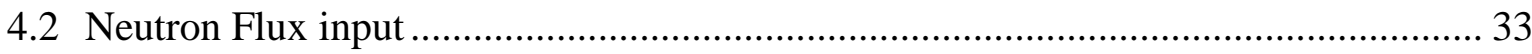

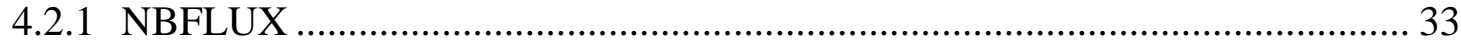

4.3 Optional Physics Input ........................................................................................ 34

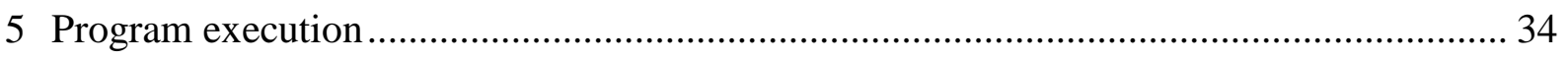

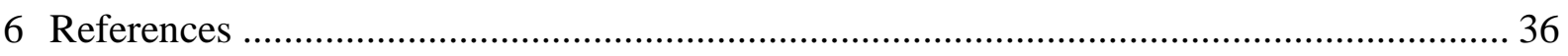

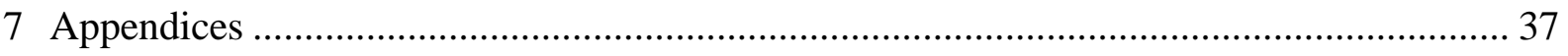

7.1 Appendix A - Sample Input files......................................................................... 37

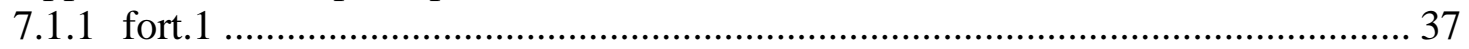

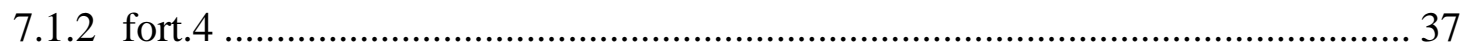

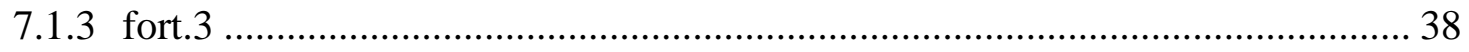

7.2 Appendix B - Core Geometry for verification problems.............................................. 40

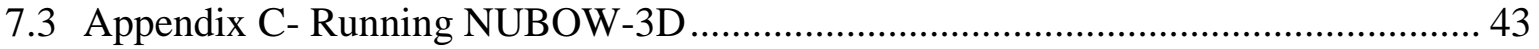

7.5 Appendix D-Detailed Explanation of Solution Process with reference to subroutines 44

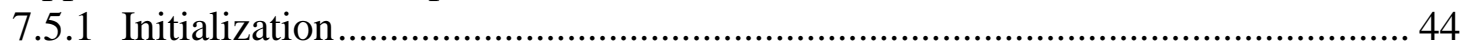

7.5.2 The Calculation Steps................................................................................. 44

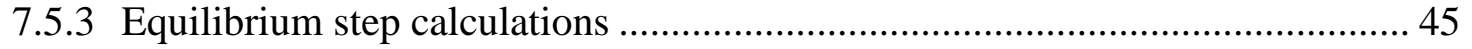

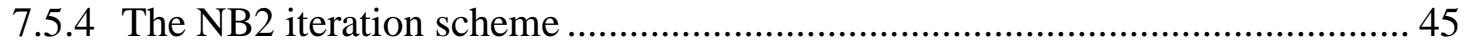

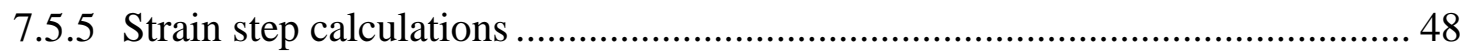

7.6 Appendix E - identification of key variables in NUBOW 2 program......................... 49

7.7 Appendix F - detailed description of input file for NUBOW 1.. Error! Bookmark not defined.

7.8 Appendix J - NB2 Subroutines 


\section{LIST OF FIGURES}

Figure 130 -degree symmetric core sector (from [1]) ............................................

Figure 2 Duct model and method of adding displacements (from [1]) .............................2

Figure 3 Load points and resolution for forces on hexagonal faces. (From [1]). ................

Figure 4 NUBOW is a suite of codes that perform the pre-processing, solving, and postprocessing functions. NUBOW1 and NUBOW2 are the original routines

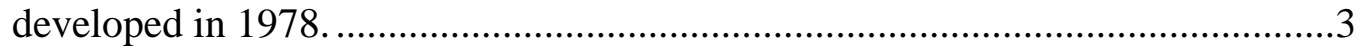

Figure 5 Full Suite of software codes that comprise the NUBOW-3D package. See text for significance of colors and dashed outlines. Numbers in blocks indicate Fortran unit numbers corresponding to input and out files..............................4

Figure 7 Description of spacing parameters ...........................................................12

Figure 8 Description of load points .......................................................................17

Figure 11 Face numbering convention in NUBOW for temperature input and sample data from formatted temperature input file.

Figure 13 Comparison of the SE-II core description and the portion used for NUBOW..31

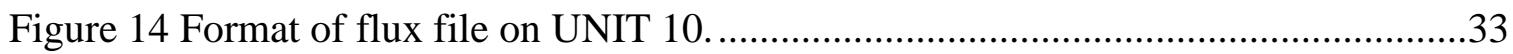

Figure 15 Node arrangement and location for load points for sample problem. Axial dimensions in inches. ...............................................................................40

Figure 16 Duct dimensions for sample problem. Dimensions in inches $/[\mathrm{mm}]$...............40

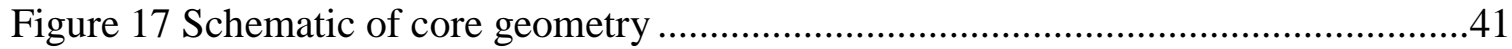

Figure 19 Flow chart of iteration sub-routine ITER8 ..............................................47

\section{LIST OF TABLE}

Table 1 List of input and output files for each component of NUBOW ..........................7

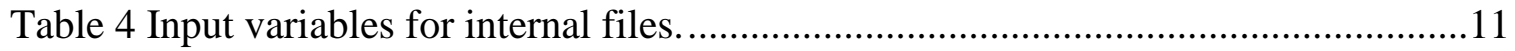

Table 5 Input variables for Core description. .......................................................... 14

Table 6 Input variables for geometric and duct description. ..........................................16

Table 7 Input variables for load point description ......................................................18

Table 9 Input values for neutron flux and reactivity information.................................21

Table 10 Input variables for strain calculations.......................................................22

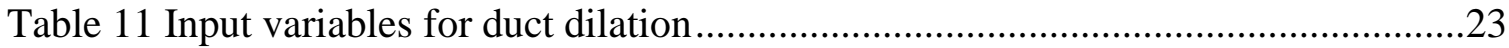




\section{Introduction}

NUBOW-3D or NUBOW is a FORTRAN code developed to model the structural response (loading and deformations) of fuel assemblies in response to the effect of thermal expansion, and irradiation swelling and creep. The main purpose of NUBOW is to assess the effectiveness of a core restraint design. NUBOW also determines the shapes of the ducts after being irradiated which provides useful information in determining the ability and ease of subsequent refueling operations. Using the detailed deformation response along with reactivity displacement worths, the software optionally can calculate the change in reactivity due to core displacements.

The NUBOW-3D code was completed in 1978. Very thorough documentation exists for this original release. Additional pre- and post- processing programs were developed in 1981 with minor modifications to the NUBOW code to allow additional operation. Minimal to no documentation exists to describe the additional coding and program modifications. Further modifications were made in 1987.

The original NUBOW manual [1] provides a very comprehensive description of the code and theory. Despite some inconsistencies due to subsequent program changes, it remains and excellent resource and the reader is referred there for a more thorough introduction to the code. The manual offers a theoretical back drop to the intended calculations. This document provides an overview of how the software is now packages as well as the required input files. Additionally and example file is provided to assist in the development of input files.

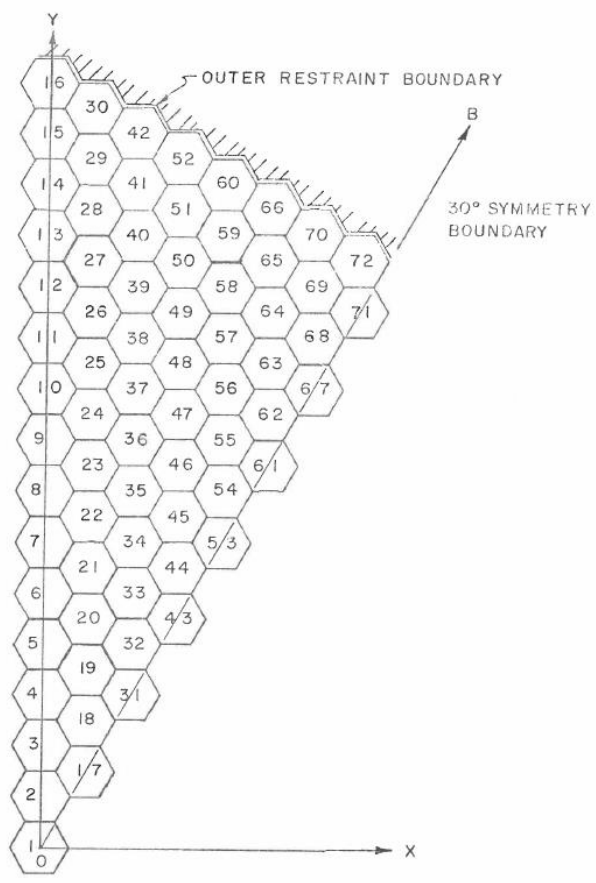

Figure 130 -degree symmetric core sector (from [1]). 
Figure 1 shows the NUBOW model of a reactor core assembly as a 30 degree symmetric model of core (Figure 1). Fuel assembly ducts are modeled as vertically oriented 3D beams with 3 space dimensions with transverse deflections determined in the X-Y plane. Axial extension is ignored. Contact between ducts and the grid plate and restraint rings is modeled via linear springs between ducts. Total displacement is the sum of the combined effects of grid plate thermal expansion, bowing due to thermal gradient across the duct cross section, inelastic strains over time, and restraints imposed by duct to duct contact as well as due to the restraint rings (see Figure 2). Due to the non-linear nature of contact, NUBOW uses an iterative solver using force equilibrium as the convergence criteria to solve for the displacement degrees of freedom.

The core temperature profile and neutron flux are inputs to the model and are provided as functions of time describing the planned operation over a specific time period. Included is the capability to study power ramp-ups (quasi-statically).

The optional net reactivity change calculation of the core is determined based on the new position of the fuel assemblies and as a post-processing step (after each solution time step). NUBOW returns duct deflections, forces on load points (Figure 3), and stresses in ducts. It includes provisions to model multiple restraint rings. The software does not include friction, off centered loading, or duct rotations.
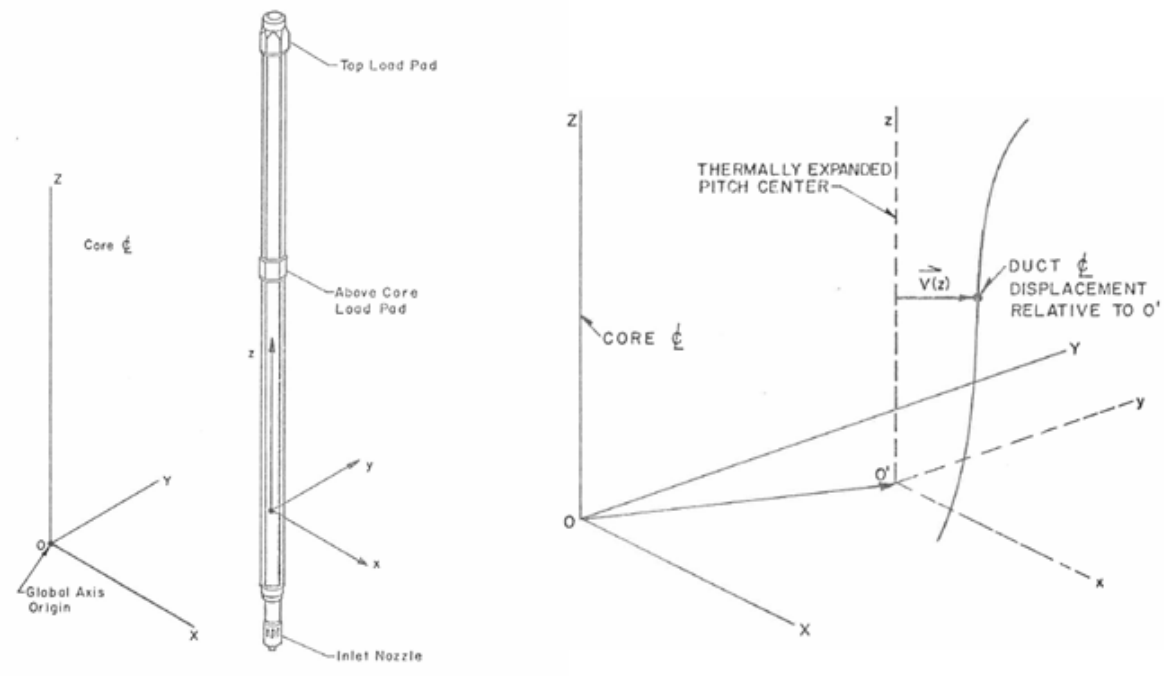

Figure 2 Duct model and method of adding displacements (from [1]) 

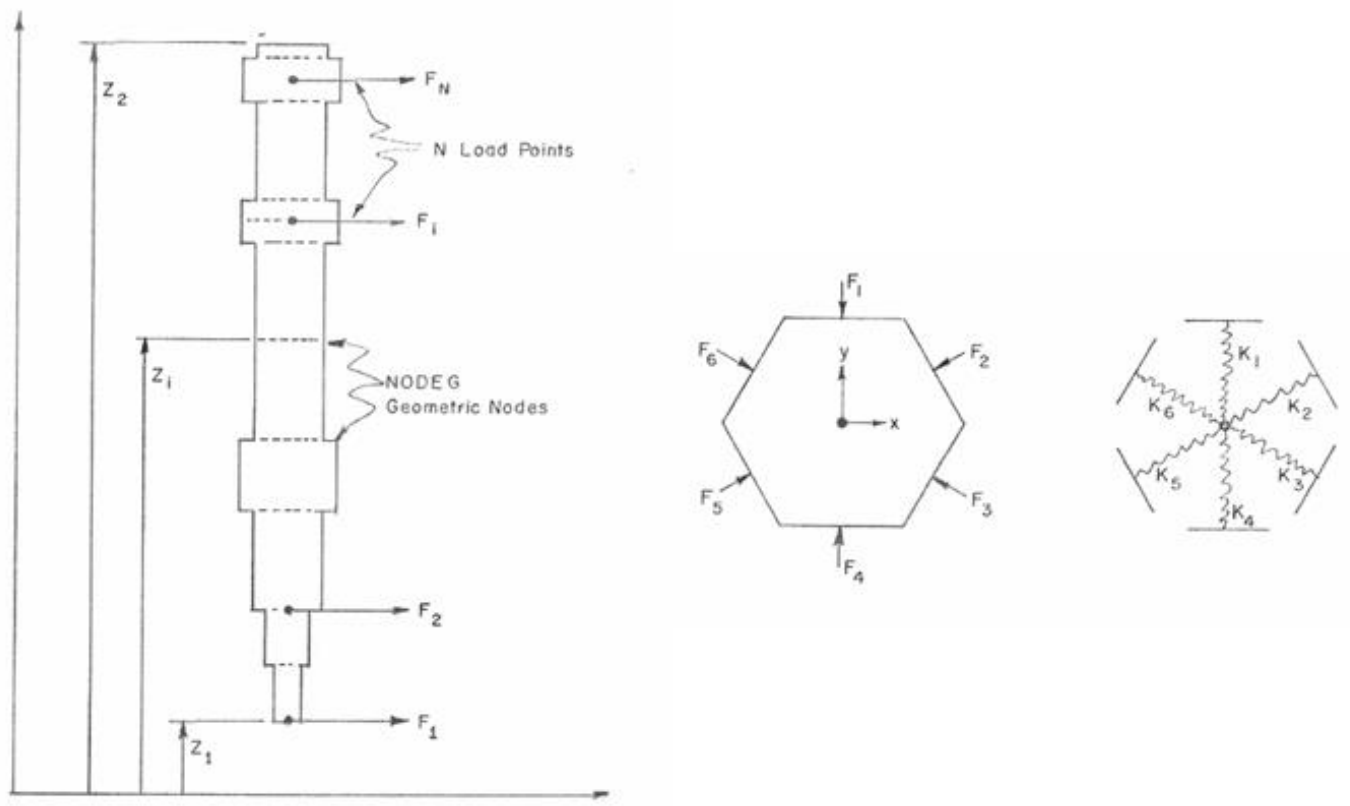

Figure 3 Load points and resolution for forces on hexagonal faces. (From [1]).

\section{Program structure and file description}

The NUBOW software is actually a collection of routines and programs that fit into one of three phases of analysis: preprocessing of user input and model creation, solver, post processing of solution data (see Figure 4). The preprocessing stage includes several codes that provide an interface to core physics codes such as to provide neutron flux and temperature data. In this report we shall use the name NUBOW to refer to this entire suite of code including the data preparation codes.

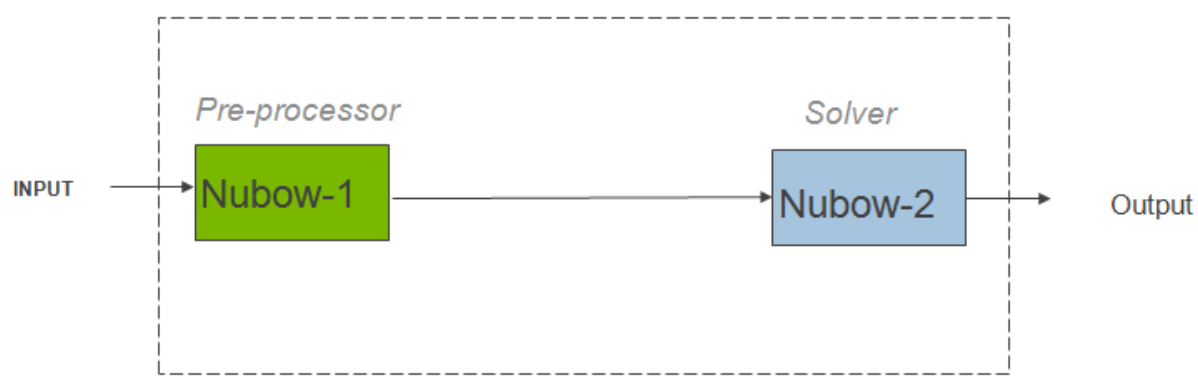

Figure 4 NUBOW is a suite of codes that perform the pre-processing, solving, and post-processing functions. NUBOW1 and NUBOW2 are the original routines developed in 1978 . 
The full set of routines and programs and related files are shown in Figure 5 and Table 1. Nubow1, or NB1, will be used to refer to the code that generates the model and prepares input for the calculation module. Nubow2, or NB2, will refer to the main code which calculates equilibrium states and inelastic strain increments.

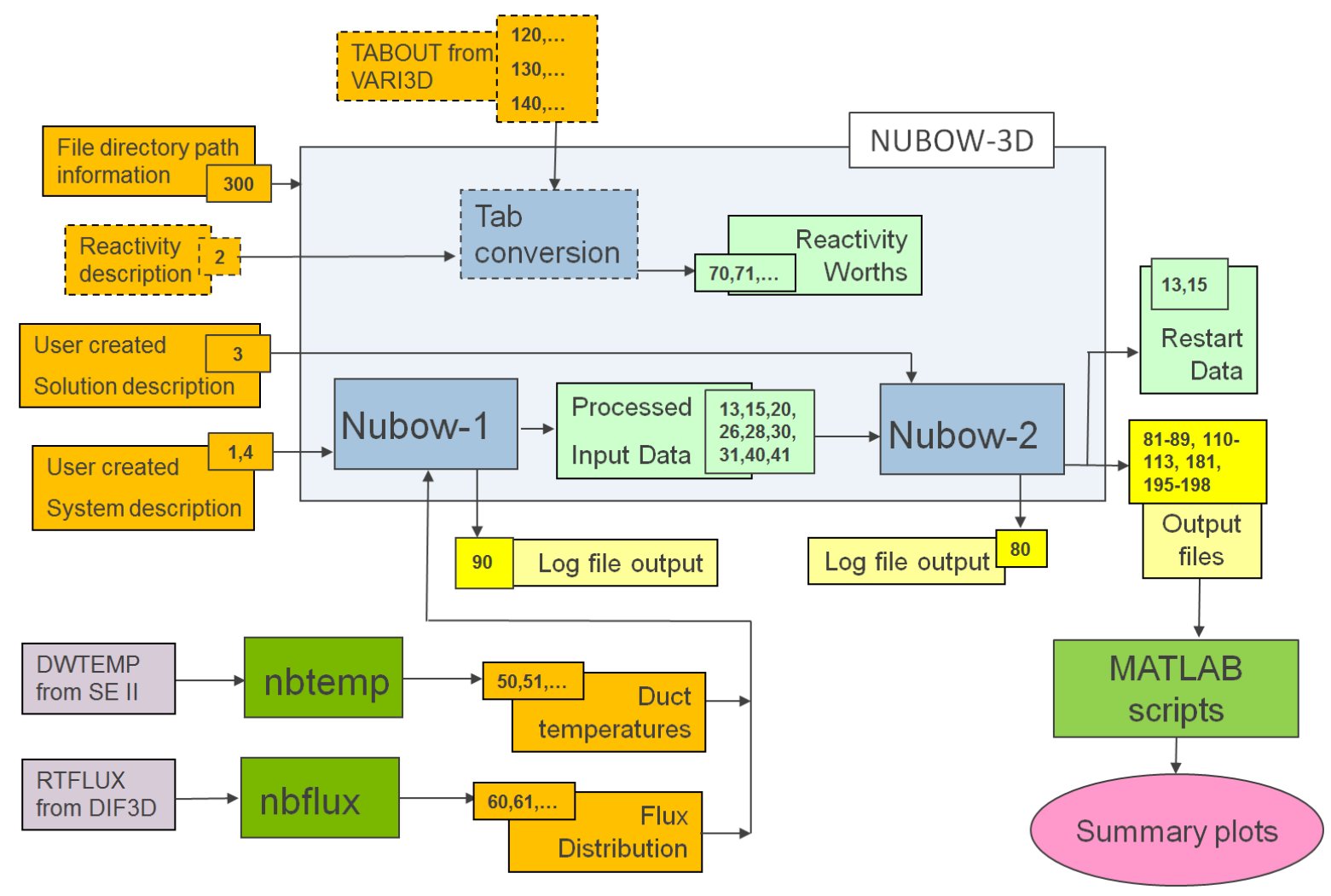

Figure 5 Full Suite of software codes that comprise the NUBOW-3D package. See text for significance of colors and dashed outlines. Numbers in blocks indicate Fortran unit numbers corresponding to input and out files.

Figure 5 provides an overview of the files needed to run a NUBOW analysis. NUBOW runs exclusively from input data files and similarly provides output only in the form of output data files. The files used and created by NUBOW can loosely be grouped as input, internal use, and output files. The input files can further be classified into user created input files and physics input files. The physics input files generally are created in another physics based analysis and require conversion to a usable format for NUBOW, normally done using some preprocessing utility. There are a large number of files associated with a NUBOW analysis although only a small number of the input files are prepared by the user and a similarly small number are of the output files are used by the user.

In the block diagram (Figure 5), the various blocks describing the files are color coded to classify the files according to purpose and method of preparation. The blocks representing 
files have a file unit number inset which refers to the corresponding Fortran file unit numbers. Table 1 lists all of the files and provides a brief description of the purpose of each file.

The color of the blocks in Figure 5 indicate the purpose and source of the various files or routines. The large light blue box labeled as NUBOW-3D describes the self-contained executable program NUBOW3D rev.3. All of the other blocks indicate files and utility functions that are located outside of NUBOW. All of these blocks outside of NUBOW make up the set of input and output files along with various pre- and post-processing utilities.

The orange blocks in the Figure 5 describe the input files needed to execute NUBOW excepting that the two orange blocks with dashed outlines are optional files related to the reactivity calculation and are not required if this option is not requested. All of the other files indicated by the orange blocks are required to execute NUBOW. The files on units 1-4, and 300 are generally created by the user and contain variables that make up Fortran namelists. Descriptions and examples of creating these files are contained in Section 3. The remaining required input files can be generated directly by the user but require precise formatting and are generally large data files. The description and format of these files is discussed further in Section 4. These files are generally the results of other physics files translated into the needed format for NUBOW and are generally created using a pre-processing utility such as NBTEMP and NBFLUX as indicated in the figure. The pre-processing (as well as post processing) functions/scripts are indicated in Figure 5 by the dark green blocks. These are a mix of standalone Fortran programs or Matlab [2] scripts.

NUBOW was developed to interface with various reactor codes developed at Argonne. These include the thermal hydraulics code Super-Energy-II (SE-II), and the neutronics codes DIF3D and VARI3D. The light purple boxes in Figure 5 indicate specific data files that are created within these codes that are used along with the above mentioned preprocessors to prepare the required input files. An exception to this coloring scheme and method exists for the displacement reactivity worth files (files120-149). This data is created from the TABOUT file of the neutronics code VARI3D and is input directly into NUBOW-3D (when the reactivity calculation option is requested). The pre-processer that converts this file into NUBOW form, tabConversion, is contained within the NUBOW-3D executable.

Within the light blue box labeled NUBOW-3D are the functions and files internal to the executable and that are transparent to the user. The blue boxes refer to functions within the program. The above mentioned tabConversion is shown within this box as are Nubow-1 and Nubow-2. The relevance of distinguishing these internal functions relates to the description in the original user manual [1]. The original user manual makes repeated references to Nubow-1 and Nubow-2. In addition, the two functions logically separate purposes between preprocessing of data (Nubow-1) and the solver (Nubow-2). With this understanding and reference to Figure 5, one can see how the input files 1,4 provide system model information (duct geometry, node locations, etc.) whereas file 3 provides solver information (time steps, ramp profiles, etc,). The light green blocks indicate files that are for internal use of NUBOW. A large set of them as indicated in the figure are output by Nubow-1 and then used as input to Nubow-2. 
The yellow blocks in the figure indicate the output files produced by NUBOW-3D. Some of these files are directly readable whereas others are intended for further post-processing to provide plots and tables of data. Much of the output data is provided in the two files: 80 and 90. These files are log files of the Nubow- 1 and Nubow- 2 execution respectively. These text based files exactly repeat the input data, and then summarize the most relevant output along the process. The other output files provide specific output data in various forms as need for a small suite of Matlab scripts which plot the data. 
Table 1 List of input and output files for each component of NUBOW.

\begin{tabular}{|c|c|c|c|c|}
\hline $\begin{array}{l}\text { USER CREATED } \\
\text { INPUT FILES }\end{array}$ & $\begin{array}{l}\text { PHYSICS INPUT } \\
\text { FILES }^{1}\end{array}$ & $\begin{array}{l}\text { INTERNAL } \\
\text { files }\end{array}$ & $\begin{array}{l}\text { OUTPUT files } \\
\text { for post } \\
\text { processing }\end{array}$ & Description \\
\hline fort. $1^{2}$ & & & & $\begin{array}{l}\text { Namelist. \&batchINPUT. Geomtric node information and initial information for } \\
\text { reactivity file }\end{array}$ \\
\hline fort. 2 & & & & $\begin{array}{l}\text { Input for converting reactivity densities calculated in VARI3D into reactivity } \\
\text { WORTH data. (only needed when selecting reactivity calculation). }\end{array}$ \\
\hline fort.3 & & & & Namelist \&START Solution information \\
\hline fort.4 & & & & Namelist. \&INPUT. Remainder of system description variables. \\
\hline \multirow[t]{12}{*}{ fort.300 } & & & & $\begin{array}{l}\text { Strings describing directory paths for the various input files and the desired } \\
\text { destination for selected output files. }\end{array}$ \\
\hline & $\begin{array}{l}\text { fort.120-.129 } \\
\text { fort } 130-.139 \\
\text { fort.140-.149 }\end{array}$ & & & $\begin{array}{l}\text { Reactivity densities for sodium, fuel, and structure for specific cycle (only needed } \\
\text { when selecting reactivity calculation). }\end{array}$ \\
\hline & fort.50-.59 & & & Formatted temperature sets (fort.9 if only one set) up to 10 sets. \\
\hline & fort.60-.69 & & & Formatted flux data. Up to 10 sets. \\
\hline & & fort.13 & & Formatted starting data. \\
\hline & & fort.15 & & Partially formatted starting data; used for restarts of nubow-2. \\
\hline & & fort.20 & & Formatted temps, bow shapes \\
\hline & & fort.26 & & Unformatted zeroed creep, swelling, fluence by cell \\
\hline & & $\begin{array}{l}\text { fort.30, } \\
\text { fort.31, .. }\end{array}$ & & Unformatted temps and bow shapes by, up to 10 sets \\
\hline & & $\begin{array}{l}\text { fort.40, } \\
\text { fort. } 41, \ldots\end{array}$ & & Unformatted temp/flux by cell, up to 10 sets \\
\hline & & fort.11 & & Internal program use \\
\hline & & fort.28 & & internal file \\
\hline
\end{tabular}

\footnotetext{
${ }^{1}$ While these files can be produced directly by the user, these files are specially formatted and normally produced from a preprocessing script or utility. ${ }^{2}$ fort.\#\# refers to a Fortran input/output file written or read within the program on the logical unit number \#\#.
} 


\begin{tabular}{|c|c|c|c|c|}
\hline $\begin{array}{l}\text { USER CREATED } \\
\text { INPUT FILES }\end{array}$ & $\begin{array}{l}\text { PHYSICS INPUT } \\
\text { FILES }^{1}\end{array}$ & $\begin{array}{l}\text { INTERNAL } \\
\text { files }\end{array}$ & $\begin{array}{l}\text { OUTPUT files } \\
\text { for post } \\
\text { processing }\end{array}$ & Description \\
\hline & & fort.70-.79 & & $\begin{array}{l}\text { Displacement WORTH values generated from tabConversion function. Up to } 10 \\
\text { sets. }\end{array}$ \\
\hline & & & fort.80 & $\begin{array}{l}\text { Program output log lists deflections, forces, and reactivity change for each step. } \\
\text { Include iteration and convergence information. }\end{array}$ \\
\hline & & & fort.81 & Used with Nub81 post processor \\
\hline & & & fort.83 & Step and iteration information for troubleshooting \\
\hline & & & fort.84 & Input for NBPOST (not used, was fort.75) \\
\hline & & & fort.85 & $\begin{array}{l}\text { Deflection information for load points. Same information written in fort. } 80 \text { but } \\
\text { without header and other information. }\end{array}$ \\
\hline & & & fort.86 & $\begin{array}{l}\text { Additional deflection information for higher resolution duct plotting of ducts } \\
\text { (was fort.82). Used for deformed row plotting. }\end{array}$ \\
\hline & & & fort.87 & reactivity data \\
\hline & & & fort.88 & used for plotting hexes using MATLAB script (was fort.86) \\
\hline & & & Fort.89 & \\
\hline & & & fort.90 & Program output listing processed data in easily readable form. \\
\hline & & & fort.81 & \\
\hline & & & fort.110,.111 & Force on face 1 for levels 3,4 \\
\hline & & & fort.112,.113 & vy for levels 3,4 \\
\hline & & & fort.181 & \\
\hline & & & fort.195 & \\
\hline & & & fort.196 & \\
\hline & & & fort.197 & \\
\hline & & & fort.198 & \\
\hline
\end{tabular}




\section{User Prepared Input files}

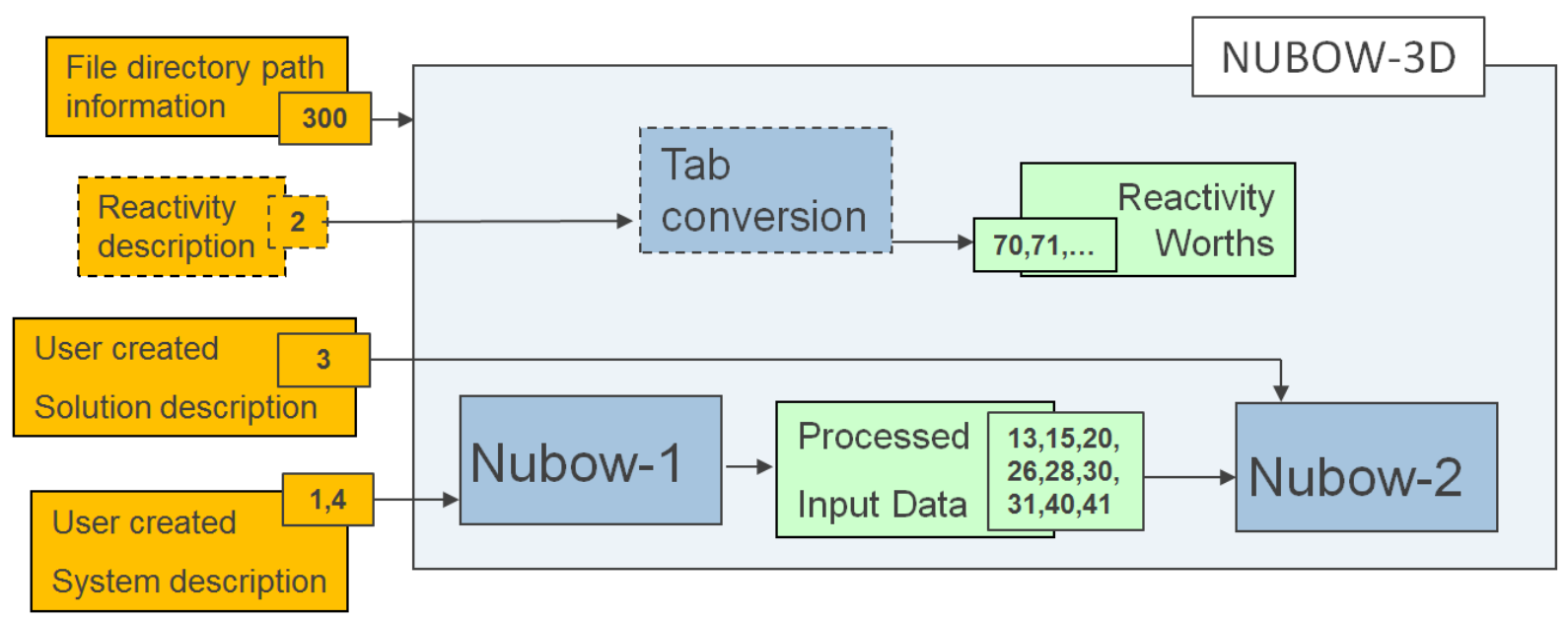

Figure 6 Block diagram isolating the user prepared input files.

The specific user prepared input files are isolated in Figure 6. For the purposes of describing and illustrating the creation of the user input files, we use and example problem of a 25-duct core. The full file is listed in Appendix A - Sample Input files. Note that Fortran loads 2D arrays in column order such. For example, for a $2 \mathrm{D}$ array $\mathrm{X}(4,6)$ loaded with sequence of values $1,4,6,7,8,9, \ldots$, corresponds to $\mathrm{X}(1,1)=1, \mathrm{X}(2,1)=4, \ldots \mathrm{X}(1,2)=8$ (the fifth value in the sequence) and so on.

\section{1 fort.300 (\&FortFileDirectories namelist)}

When NUBOW executes, the first action is to look at the fort.300 file to identify the directory location of the input files as well as to determine where the output files should be stored. The purpose of this is to allow files to be shared from different locations as well as stored in different locations. NUBOW will look for the fort.300 file in the directory where the executable is located. Table 2 describes the variables for the fort.300 file. Similarly, the internal files and output files used only for troubleshooting are written to the same directory.

The saveFileName variable is a string that is used as a prefix to identify the output files with a particular case. In the example file text below, this variable is input as 'Sample_. The result

of this is that selected output files such as fort.80 are saved with the filename Sample_80.txt. 


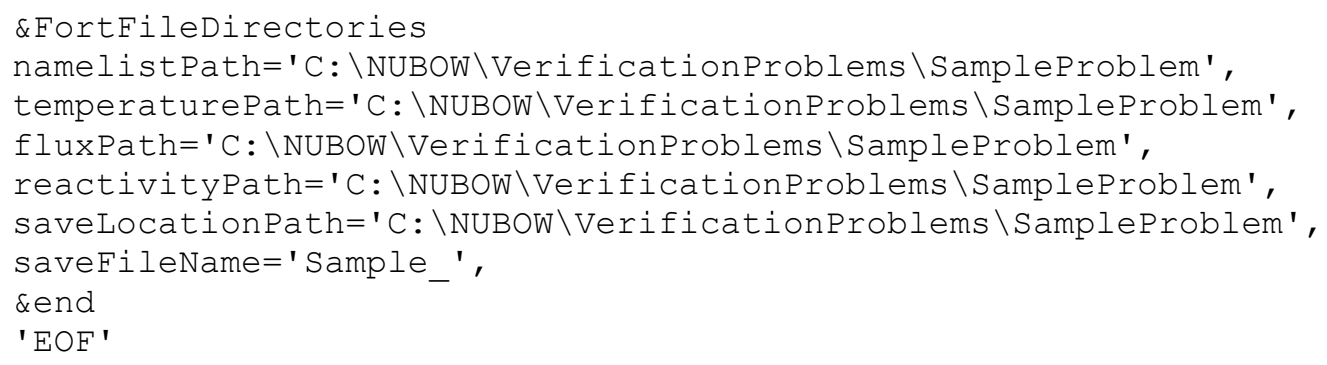

Table 2 Input variables for fort.300 file

\begin{tabular}{|l|l|}
\hline namelistPath & $\begin{array}{l}\text { Directory path for the user created files } \\
\text { (fort.1-.4) }\end{array}$ \\
\hline temperaturePath & $\begin{array}{l}\text { Directory path for the temperature files } \\
\text { (fort.50-.59) }\end{array}$ \\
\hline fluxPath & $\begin{array}{l}\text { Directory path for the fast neutron flux files } \\
\text { (fort.50-.59) }\end{array}$ \\
\hline saveLocationPath & $\begin{array}{l}\text { Directory path for the reactivity density files } \\
\text { (fort.120-.149) }\end{array}$ \\
\hline saveFileName & $\begin{array}{l}\text { Directory path where the Output files will be } \\
\text { stored.(fort.50-.59) }\end{array}$ \\
\hline
\end{tabular}

\section{2 fort.1 (\&batchInput namelist)}

The fort. 1 input file contains the geometric node information and some general information for the optional reactivity calculation.

\section{Problem Title}

sTitle=

'SMALL CORE SAMPLE PROBLEM; 25 DUCTS ',

\section{Geometric Node Information}

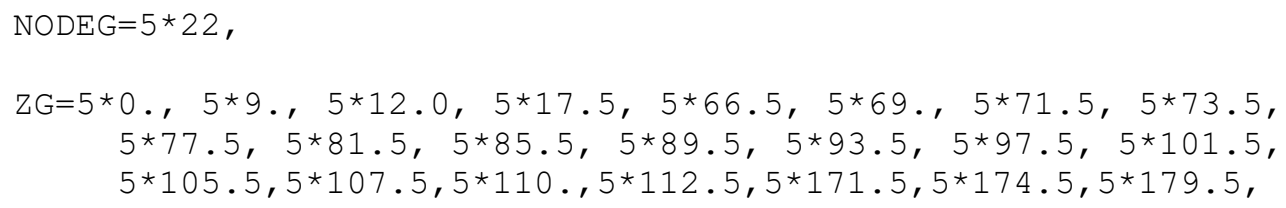


Table 3 Description for variables used in fort.1 \&batchInput namelist.

\begin{tabular}{|c|c|c|}
\hline STITLE & Problem title, up to 80 characters & \\
\hline NODEG(5) & $\begin{array}{l}\text { Array Specifying the Number of } \\
\text { Geometric Nodes for Each } \\
\text { Geometric Type ( } 5 \text { types) }\end{array}$ & $\begin{array}{l}\text { Geometric nodes are axial locations } \\
\text { where the dimensions or stiffness } \\
\text { properties of the assembly change. }\end{array}$ \\
\hline ZG(5,NMAX) & $\begin{array}{l}\text { Axial coordinates of geometric } \\
\text { nodes for up to } 5 \text { duct types }\end{array}$ & $\begin{array}{l}\text { Note that the properties of each } \\
\text { geometric section are defined be two } \\
\text { nodes. }\end{array}$ \\
\hline
\end{tabular}

\section{3 fort.4 (\&INPUT namelist)}

File information

$$
\mathrm{N} 2=20, \mathrm{N3}=26, \mathrm{~N} 4=27, \mathrm{N5}=28 \text {, }
$$

Table 4 Input variables for internal files.

\begin{tabular}{|c|c|}
\hline N2 & Input/Output File Number for System Data \\
\hline N3 & Input/Output File Number for Cell Strains and Fluences \\
\hline N4 & $\begin{array}{c}\text { Input/Output File Number for Cell Geometry, Flux, \& } \\
\text { Temperature }\end{array}$ \\
\hline N5 & Input/Output File Number for Cell Strains and Fluences \\
\hline
\end{tabular}

\section{Core Description}

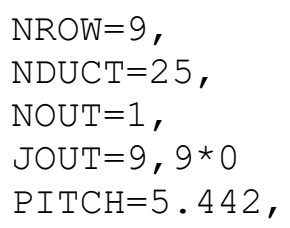




\section{$\underline{\text { Support plate and restraint ring description }}$}
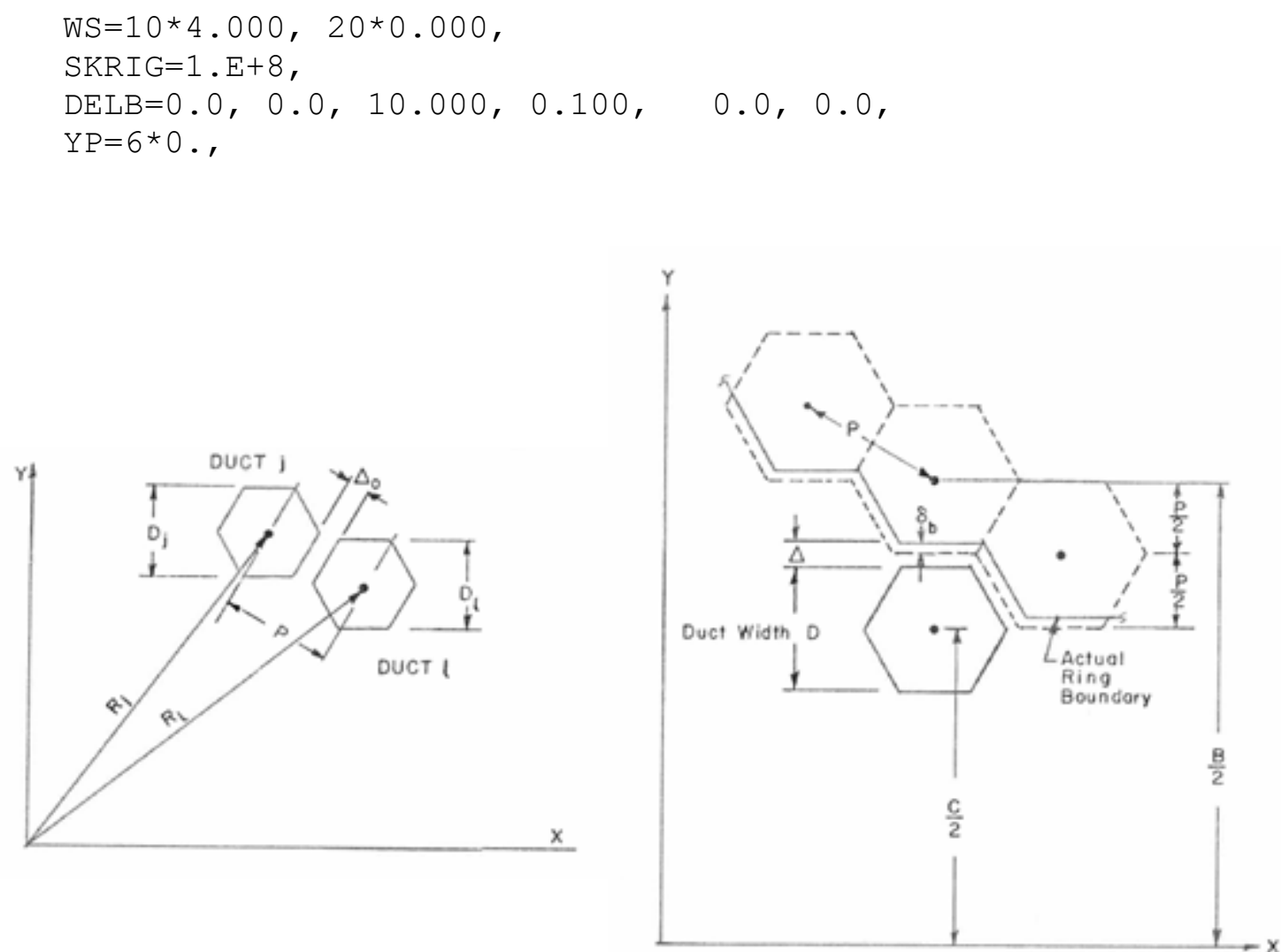

Figure 7 Description of spacing parameters. $\Delta=\delta_{b}+\left(\frac{P-D}{2}\right)$ 


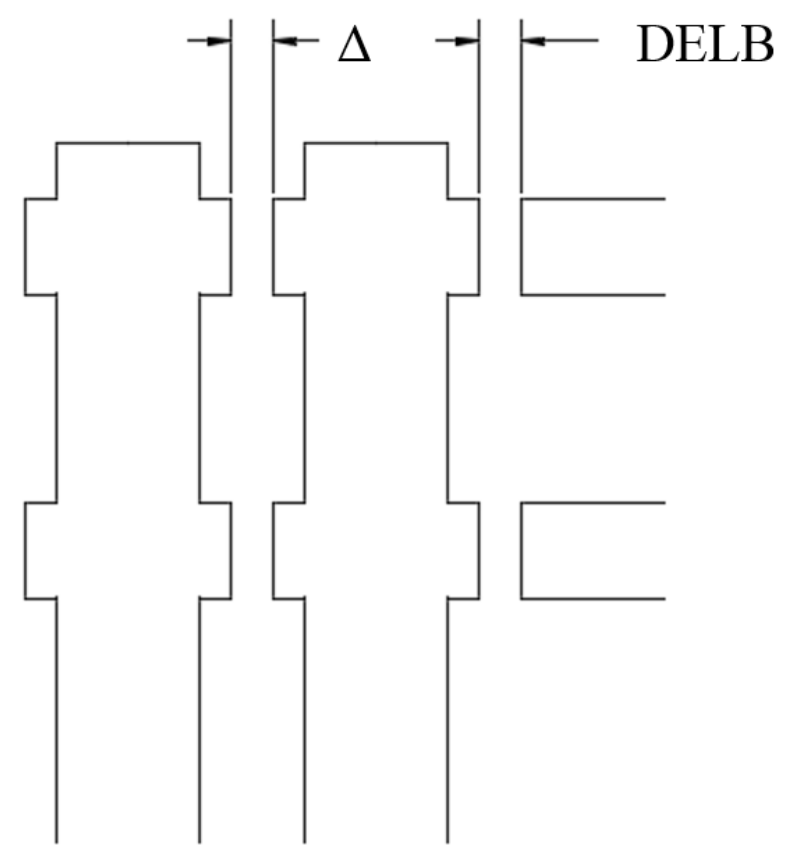

Figure 8 Additional illustration of DELB with restraint ring. 
Table 5 Input variables for Core description.

\begin{tabular}{|c|c|c|}
\hline NROW & number of rows & The center assembly is row 1 \\
\hline NDUCT & $\begin{array}{l}\text { Number of assemblies in a Full } 30^{\circ} \\
\text { Sector; NDUCT is } \\
\text { EQUIVALENCE to M, see NB1 } \\
\text { Line } 8700 .\end{array}$ & $\begin{array}{l}\text { If NROW is even, NDUCT is equal } \\
\text { to twice the sum of } 1 \text { to NROW/2; if } \\
\text { NROW is odd, NDUCT is the } \\
\text { number for }(N R O W-1)+ \\
(N R O W+1) / 2\end{array}$ \\
\hline NOUT & $\begin{array}{l}\text { Number of assemblies deleted from } \\
\text { the outer rows to make the array } \\
\text { circular. }\end{array}$ & \\
\hline JOUT(10) & $\begin{array}{l}\text { Individual assembly numbers of } \\
\text { assemblies deleted from the outer } \\
\text { rows. }\end{array}$ & $\begin{array}{l}\text { This array must have NOUT values } \\
\text { between } 1 \text { and NDUCT }\end{array}$ \\
\hline PITCH & $\begin{array}{l}\text { Uniform Grid Pitch of System at } \\
\text { Base Temperature T0 }\end{array}$ & $\begin{array}{l}\text { Note: all dimensions are expanded } \\
\text { based on current temperatures and } \\
\text { material properties. }\end{array}$ \\
\hline $\operatorname{DELB}(6)$ & $\begin{array}{l}\text { Additional boundary ring clearance } \\
\text { (for up to six rings) beyond that } \\
\text { clearance that occurs from close } \\
\text { packed ducts of width P. Clearance } \\
\text { at boundary become (PITCH-DG)/2 } \\
\text { if DELB=0. (see Figure } 7 \text { and } \\
\text { Figure 8). }\end{array}$ & $\begin{array}{l}\text { The TLP clearance is a key factor in } \\
\text { core restraint performance during } \\
\text { startup transients. Increasing DELB } \\
\text { increases the outer gap for a looser } \\
\text { core. A suitable gap at the ACLP is } \\
\sim 1 \text { inch; A rule of thumb for the TLP } \\
\text { gap is } 0.010 \text { in. times NROW. }\end{array}$ \\
\hline $\mathrm{YP}(6)$ & $\begin{array}{l}\text { Restraint Ring (Yoke) Position for } \\
\text { Up to } 6 \text { Levels }\end{array}$ & $\begin{array}{l}\text { Positive YP increases the boundary } \\
\text { gap, see [1] p19. This is a relic from } \\
\text { the days of active core restrain } \\
\text { concepts. }\end{array}$ \\
\hline WS $(5,6)$ & $\begin{array}{l}\text { Circular Diameter of Support Point } \\
\text { Receptacles, } 5 \text { Assembly Types } \\
\text { and up to } 6 \text { support points. } \\
\text { WS(type, support point) }\end{array}$ & $\begin{array}{l}\text { Measured at temperature T0; must be } \\
\geq \text { DG for the assembly type at the } \\
\text { support elevation. A suitable choice } \\
\text { is WS }=100.5 \% \text { of DG. }\end{array}$ \\
\hline
\end{tabular}




\section{Assembly geometric description}

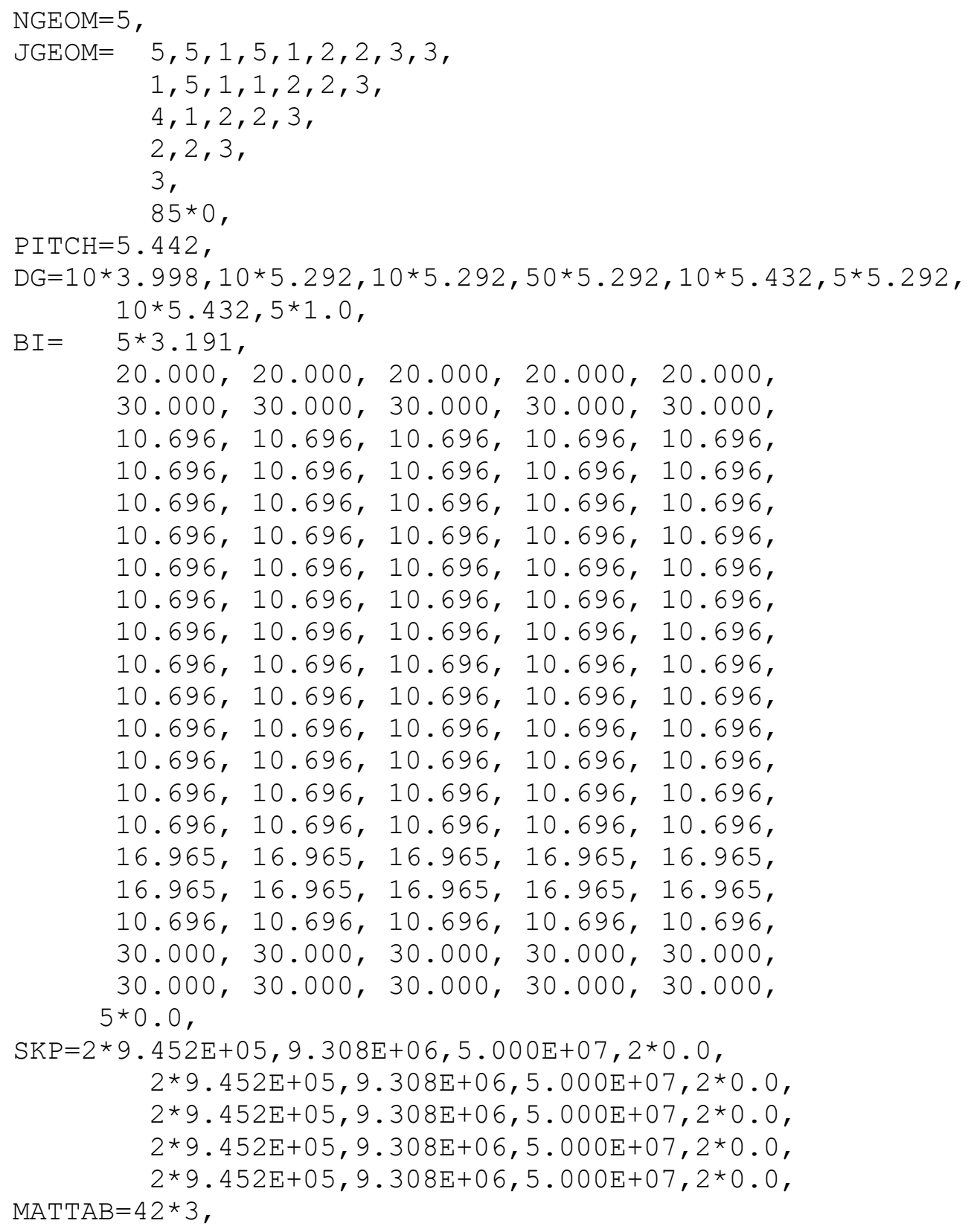


Table 6 Input variables for geometric and duct description.

\begin{tabular}{|c|c|c|}
\hline NGEOM & $\begin{array}{l}\text { Number of Different } \\
\text { Geometric Duct Types }\end{array}$ & $\begin{array}{l}\text { Driver assemblies, control assemblies, } \\
\text { reflector assemblies, etc. may have } \\
\text { different properties. }\end{array}$ \\
\hline JGEOM(110) & $\begin{array}{l}\text { Array specifying the geometric } \\
\text { type number for each } \\
\text { assembly. }\end{array}$ & $1 \leq \mathrm{JGEOM} \leq \mathrm{NGEOM}$ \\
\hline $\begin{array}{l}\text { BI (5,NMAX) } \\
\text { BI (TYPE,NODE) }\end{array}$ & $\begin{array}{l}\text { Duct Bending Inertia for the } \\
\text { section above each geometric } \\
\text { node. }\end{array}$ & $\begin{array}{l}\text { Second moment of area for the } \\
\text { structurally active section. For a thin } \\
\text { walled hexagon, } B I=(5 / 6 \sqrt{3}) *\left[D^{3} t-\right. \\
\left.3 D^{2} t^{2}+4 \mathrm{Dt}^{3}-2 t^{4}\right] \\
\text { D=DG(type,node) } \\
t=W T(\text { type,node) }\end{array}$ \\
\hline $\begin{array}{l}\text { DG(5,NMAX) } \\
\text { DG (TYPE,NODE) }\end{array}$ & $\begin{array}{l}\text { Duct Across-Flats Dimension } \\
\text { for the section above each } \\
\text { geometric node. }\end{array}$ & $\begin{array}{l}\text { Outside across-flats dimension for } \\
\text { hexagonal sections; outside diameter } \\
\text { for round sections. At the TLP and } \\
\text { ACLP the diameter determines the } \\
\text { core porosity. A Rule of thumb is DG } \\
\sim 99.5 \% \text { of PITCH. }\end{array}$ \\
\hline $\begin{array}{l}\text { SKP(6,5) } \\
\text { SKP(LOAD PT., } \\
\text { GEOM. TYPE) }\end{array}$ & $\begin{array}{l}\text { Contact Stiffness for at load } \\
\text { points for } 5 \text { geometry types. } \\
\text { (LOAD POINT, GEOMETRY } \\
\text { TYPE) }\end{array}$ & $\begin{array}{l}\text { (load,type) all springs are the same } \\
\text { for each face at a specific load point } \\
\text { level }\end{array}$ \\
\hline MATTAB $(6,7)$ & $\begin{array}{l}\text { Material designation for each } \\
\text { assembly type and support and } \\
\text { "duct" }\end{array}$ & $\begin{array}{l}\text { MATTAB }(5 \text { load types }+ \text { support, } 6 \\
\text { load points }+ \text { duct }\end{array}$ \\
\hline
\end{tabular}


Table 7 Material designations for MATTAB

\begin{tabular}{|c|l|}
\hline Material Designation & Description \\
\hline 1 & AISI 16, 20\% CW \\
\hline 2 & Alloy D9, 20\% CW \\
\hline 3 & Alloy HT-9, NSM Rev. 0,0 (26,26) \\
\hline 4 & HT-9 HEDL-TC-2845, Ju. 1986 \\
\hline 5 & \\
\hline 6 & IAEA Verification Problem Material \\
\hline 7 & HT-9 \\
\hline 8 & SS 316 \\
\hline
\end{tabular}

\section{Load and support points}

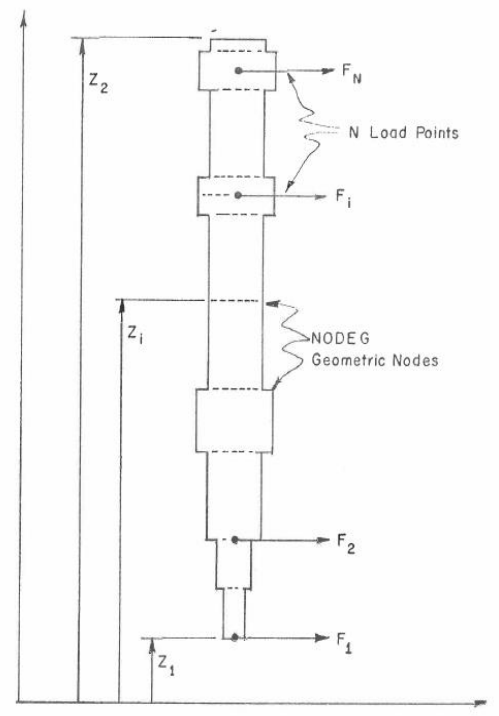

Figure 9 Description of load points

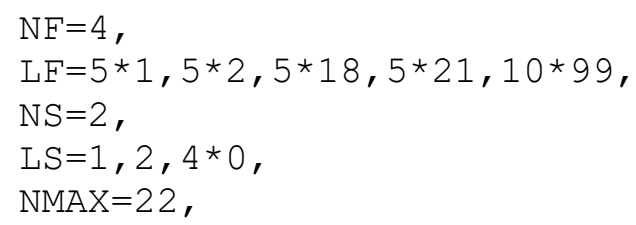


Table 8 Input variables for load point description

\begin{tabular}{|l|l|l|}
\hline NF & $\begin{array}{l}\text { Number of Axial Locations (geometric } \\
\text { nodes) at which Forces May Act (Load } \\
\text { Points). Includes support points }\end{array}$ & $\begin{array}{l}\text { Number of axial locations where } \\
\text { forces are applied ( <6). NF }>4 .\end{array}$ \\
\hline $\begin{array}{l}\text { LF(5,6) } \\
{[\text { type,force }} \\
\text { point }]= \\
\text { Geometric } \\
\text { node }\end{array}$ & $\begin{array}{l}\text { Array containing axial Locations } \\
\text { (Geometric Node Numbers) of Load } \\
\text { Points for 5 Geometric Types } \\
\text { Includes support points. }\end{array}$ & $\begin{array}{l}\text { Number of Support Points (Circular } \\
\text { Receptacles) }\end{array}$ \\
\hline $\begin{array}{l}\text { NS(5) } \\
\text { NMAX }\end{array}$ & $\begin{array}{l}\text { Largest number of nodes (geometric, } \\
\text { strain or thermal) for any assembly } \\
\text { type in the array. }\end{array}$ & Limited to 25. \\
\hline $\begin{array}{l}\text { LS(6) [support } \\
\text { point }]=\text { load } \\
\text { point }\end{array}$ & $\begin{array}{l}\text { Axial Locations (Contact Force } \\
\text { Numbers LF) of Support Points (load } \\
\text { points not geometric nodes). Support } \\
\text { point locations are same for all ducts }\end{array}$ & These do not change by type. \\
\hline
\end{tabular}


Thermal description

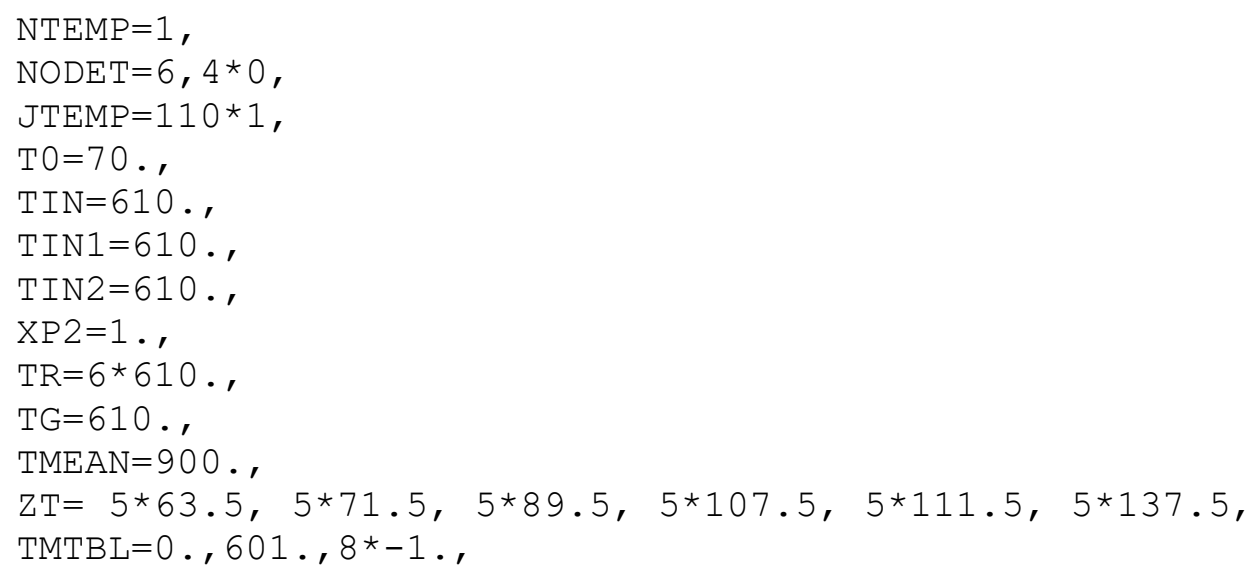


Table 9 Input variables for thermal description.

\begin{tabular}{|c|c|c|}
\hline NTEMP & $\begin{array}{l}\text { Number of Different } \\
\text { Thermal Duct Types }\end{array}$ & \\
\hline NODET(5) & $\begin{array}{l}\text { Array Specifying the } \\
\text { Number of Thermal } \\
\text { Nodes for Each } \\
\text { Thermal Type }\end{array}$ & $\begin{array}{l}\text { Thermal nodes are axial locations where } \\
\text { temperatures are input. }\end{array}$ \\
\hline JTEMP(110) & $\begin{array}{l}\text { Array of Thermal } \\
\text { Type Numbers for } \\
\text { Each Duct }\end{array}$ & $\begin{array}{l}\text { JTEMP }(4)=6 \text { implies } 6 \text { thermal nodes for } \\
\text { thermal type } 4 \text {. } \\
1 \leq \text { JTEMP } \leq \text { NTEMP }\end{array}$ \\
\hline $\mathrm{ZT}$ & $\begin{array}{l}\text { Axial Coordinates of } \\
\text { Thermal Nodes for } \\
\text { Up to } 5 \text { Types }\end{array}$ & $\begin{array}{l}\text { Temperatures are assumed to be at TIN (or based } \\
\text { on the power and flow rates for inlet } \\
\text { temperature) below the first thermal node. } \\
\text { Above the first node the temperatures vary } \\
\text { linearly between nodes and are extrapolated } \\
\text { above the final node. }\end{array}$ \\
\hline T0 & Base temperature. & Used for thermal expansion calculations \\
\hline $\begin{array}{l}\mathrm{TR}(\text { number of } \\
\text { restraint rings } \\
<=6)\end{array}$ & $\begin{array}{l}\text { Uniform restraint } \\
\text { ring temperature }\end{array}$ & $\begin{array}{l}\text { Restraint ring temperatures depend on the reactor } \\
\text { thermal design. Normally TR is greater than TG } \\
\text { and less than the mixed mean outlet temperature. }\end{array}$ \\
\hline TG & $\begin{array}{l}\text { Grid plate } \\
\text { temperature }\end{array}$ & at $100 \%$ power \\
\hline TIN & $\begin{array}{l}\text { Reactor Inlet } \\
\text { Temperature }\end{array}$ & \\
\hline TIN1 & $\begin{array}{l}\text { Reactor Inlet } \\
\text { Temperature at Zero } \\
\text { Power }\end{array}$ & See p54-55 in [1] \\
\hline TIN2 & $\begin{array}{l}\text { Reactor Inlet } \\
\text { Temperature at Full- } \\
\text { flow Breakpoint }\end{array}$ & See p54-55 in [1] \\
\hline TMEAN & $\begin{array}{l}\text { Temperature used } \\
\text { for thermal } \\
\text { expansion } \\
\text { calculations if } \mathrm{T} \leq 0 \text {. }\end{array}$ & see TEXP. see STRAIN \\
\hline XP2 & breakpoint & \\
\hline TMTBL & & \\
\hline
\end{tabular}


Neutron Flux Input

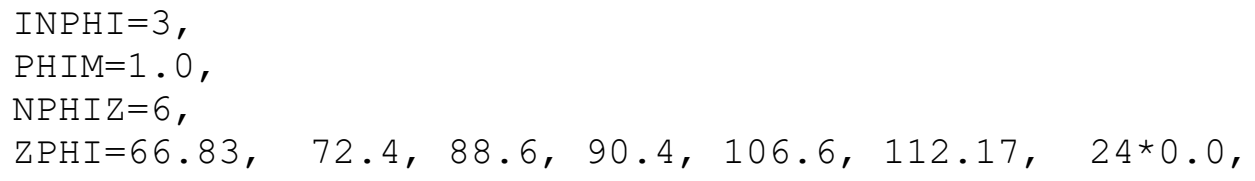

Table 10 Input values for neutron flux and reactivity information.

\begin{tabular}{|l|l|l|}
\hline INPHI & 2 implies 1 ZPHI location. & \\
\hline PHIM & Flux Distribution Scaling Factor & \\
\hline NPHIZ & $\begin{array}{l}\text { Number of Input Data Points Defining Axial } \\
\text { Flux Distribution }\end{array}$ & \\
\hline ZPHI(NPHIZ) & Axial Locations for Input Flux Data Points & \\
\hline
\end{tabular}

\section{$\underline{\text { Strain description }}$}

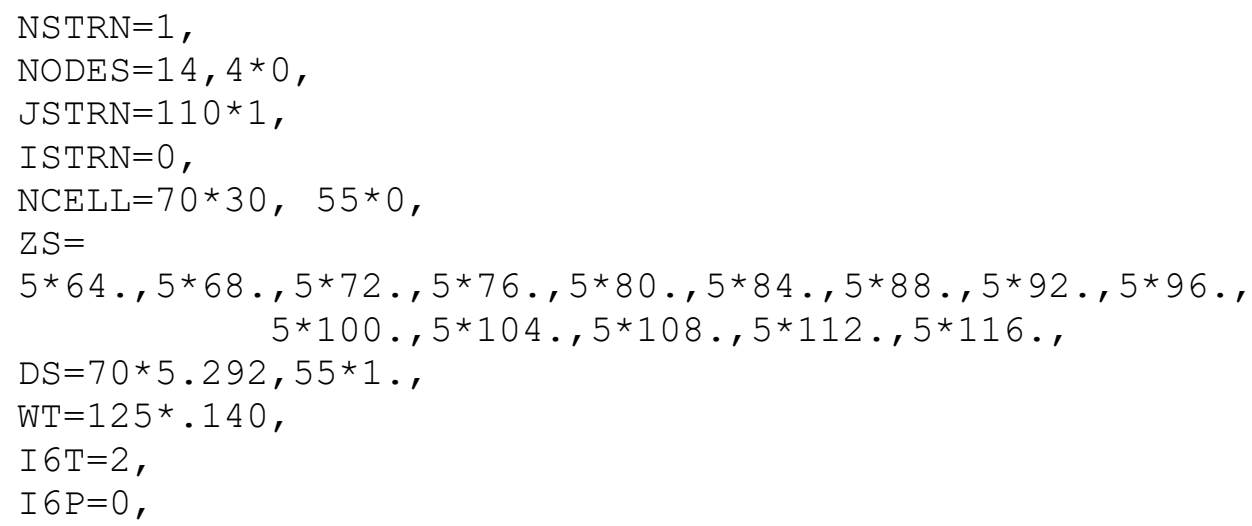

I6T is used for thermal bow (BOWSHP) and strain cells (CALC from NUBOW1->SLICES) 

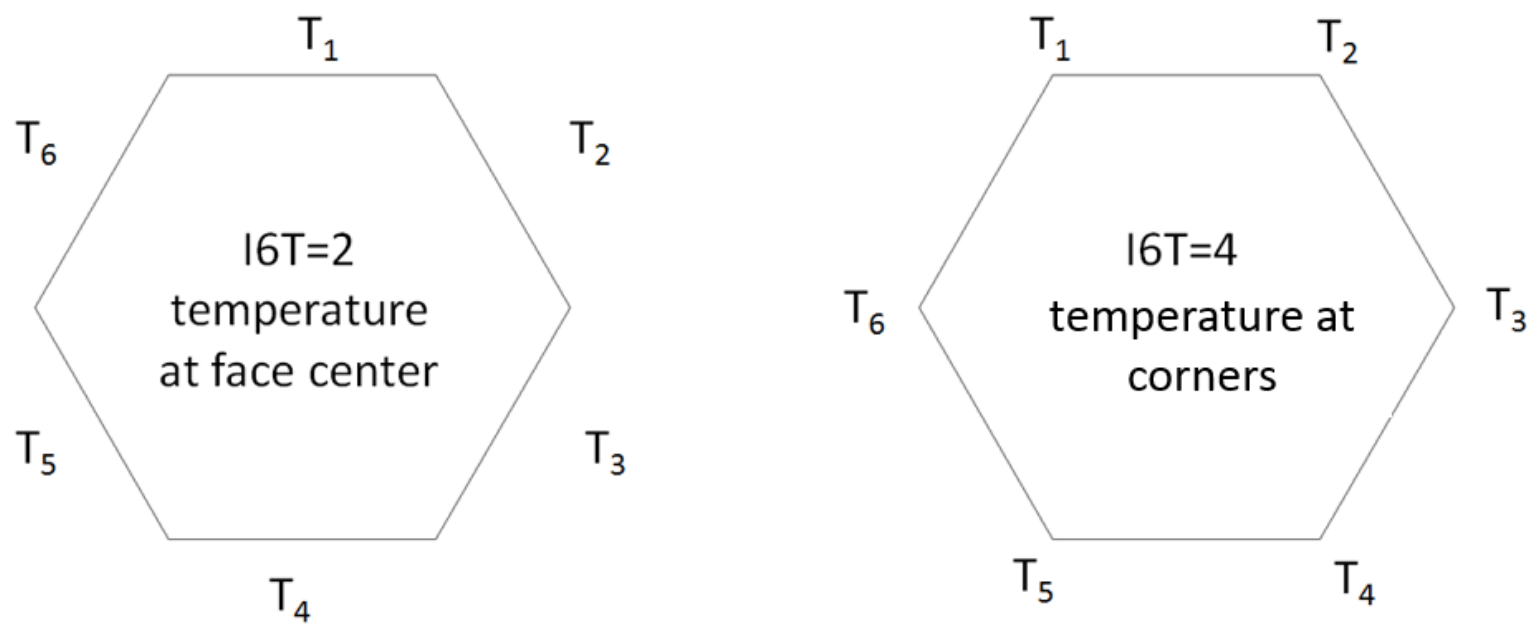

Figure 10 Schematic of temperature assignment based upon variable I6T.

Table 11 Input variables for strain calculations.

\begin{tabular}{|c|c|c|c|}
\hline VARIABLE & Description & Comment & DEFAULT \\
\hline NSTRN & $\begin{array}{l}\text { Number of Different } \\
\text { Strain Duct Types }\end{array}$ & $\begin{array}{l}\text { Different strain types } \\
\text { allow for more } \\
\text { detailed strain } \\
\text { calculations for some } \\
\text { assemblies. }\end{array}$ & \\
\hline JSTRN(110) & $\begin{array}{l}\text { Array of Strain Type } \\
\text { Numbers for Each Duct }\end{array}$ & & \\
\hline NODES(5) & $\begin{array}{l}\text { Array Specifying the } \\
\text { Number of Strains } \\
\text { Nodes for Each Strain } \\
\text { Type }\end{array}$ & $\begin{array}{l}\text { Curvature of the } \\
\text { "inelastic beam" is } \\
\text { zero below the first } \\
\text { strain node and varies } \\
\text { linearly between strain } \\
\text { nodes. See [1], pp 40- } \\
41 \text {. }\end{array}$ & \\
\hline NCELL(5,NMAX) & $\begin{array}{l}\text { Number of Strain Cells } \\
\text { at Each Strain Node for } \\
5 \text { Strain Types }\end{array}$ & $\begin{array}{l}\text { This must be a } \\
\text { multiple of six. See } \\
{[1], \text { pp } 29-40 .}\end{array}$ & \\
\hline $\mathrm{ZS}(5, \mathrm{NMAX})$ & $\begin{array}{l}\text { Axial Coordinates of } \\
\text { Strain Nodes for Up to } 5 \\
\text { Types }\end{array}$ & & \\
\hline $\mathrm{DS}(5, \mathrm{NMAX})$ & $\begin{array}{l}\text { Assembly Across-Flats } \\
\text { Dimension at Strain } \\
\text { Nodes }\end{array}$ & $\begin{array}{l}\text { DS should be } \\
\text { consistent with DG }\end{array}$ & \\
\hline
\end{tabular}




\begin{tabular}{|c|c|c|c|}
\hline WT(5,NMAX) & $\begin{array}{l}\text { Assembly Wall } \\
\text { Thickness at Strain } \\
\text { Nodes }\end{array}$ & & \\
\hline I6T & $\begin{array}{l}\text { Method of temperature } \\
\text { assignment/interpolation } \\
\text { over hexagonal cross } \\
\text { sections at each thermal } \\
\text { node. }\end{array}$ & $\begin{array}{l}\text { Input temperatures } \\
\text { applied at: } \\
\text { - }(\mathrm{I} 6 \mathrm{~T}=2) \text { face center. } \\
\text { - }(\mathrm{I} 6 \mathrm{~T}=4) \text { hexagon } \\
\text { corners with linear } \\
\text { variation along edge. } \\
\text { (See Figure 10) }\end{array}$ & 2 \\
\hline I6P & $\begin{array}{l}\text { Use linear flux variation } \\
\text { option for strain cells }\end{array}$ & & 0 \\
\hline
\end{tabular}

Duct dilation (bulging)

$\mathrm{ABLG} 1=0.0284, \mathrm{ABLG} 2=0.0791, \mathrm{PIN}=30 ., \mathrm{POUT}=0$. ,

Table 12 Input variables for duct dilation

\begin{tabular}{|l|l|l|}
\hline ABLG1 & $\begin{array}{l}\text { Dilation Pressure Compliance } \\
\text { Factor }\end{array}$ & $\begin{array}{l}\text { See [1]; also input to NB2 via NAMELIST } \\
\text { \&START }\end{array}$ \\
\hline ABLG2 & $\begin{array}{l}\text { Dilation Force Compliance } \\
\text { Factor }\end{array}$ & $\begin{array}{l}\text { See [1]; also input to NB2 via NAMELIST } \\
\text { \&START }\end{array}$ \\
\hline POUT & $\begin{array}{l}\text { Reactor Outlet Pressure at } \\
\text { Highest Load Point (LF=NF) }\end{array}$ & Used for Duct Dilation \\
\hline PIN & $\begin{array}{l}\text { Reactor Inlet Pressure at } \\
\text { Lowest Load Point (LF=1) }\end{array}$ & Used for Duct Dilation \\
\hline
\end{tabular}

Symmetry

\begin{tabular}{|l|l|l|}
\hline ISYM & $\begin{array}{l}\text { Flag indicating symmetric } \\
\text { model }\end{array}$ & $\begin{array}{l}-0 \text { indicates non-symmetric core and } \\
\text { requires duct layout to be input specifically } \\
\text { (see below) } \\
-1 \text { implies } 30 \text { degree core symmetry. }\end{array}$ \\
\hline
\end{tabular}

Example of duct layout as input and properly formatted for fort.4 file using the ISYMM=0 (non-symmetry) option. Format is: (I5, 2X,6I5). Data is read in via the Add subroutine.

Syntax: duct / neighbor 1: neighbor 6 
Neighbors are associated with face numbering, neighbor 1 is opposite face 1, etc. Face '200' indicates restraint ring boundary, '-\#\#' face indicates symmetry duct. Ducts must be entered in order, 1,2, without skipping a duct. No ducts out ??

Matlab file 'symBasis.m' will plot the text file with same format as a verification of the proper addressing scheme.

\begin{tabular}{rrrrrrr} 
\&END & \multicolumn{1}{c}{} & & & \\
1 & 2 & 3 & 200 & 200 & 200 & 200 \\
2 & 3 & 8 & -2 & 1 & 200 & 200 \\
3 & 4 & 9 & 8 & 2 & 200 & 200 \\
4 & 5 & 10 & 9 & 3 & 200 & 200 \\
5 & 6 & 11 & 10 & 4 & 200 & 200 \\
6 & 7 & 12 & 11 & 5 & 200 & 200 \\
7 & 200 & 200 & 12 & 6 & 200 & 200 \\
8 & 9 & -9 & -3 & -2 & 2 & 3 \\
9 & 10 & 13 & -9 & 8 & 3 & 4 \\
10 & 11 & 14 & 13 & 9 & 4 & 5 \\
11 & 12 & 15 & 14 & 10 & 5 & 6 \\
12 & 200 & 200 & 15 & 11 & 6 & 7 \\
13 & 14 & -11 & -10 & -9 & 9 & 10 \\
14 & 15 & 16 & -11 & 13 & 10 & 11 \\
15 & 200 & 200 & 16 & 14 & 11 & 12 \\
16 & 200 & 200 & -15 & -11 & 14 & 15 \\
'EOF' & & & & & &
\end{tabular}

\section{4 fort.3 (\&START namelist)}

The solver portion of NUBOW (Nubow-2) is configured through the \&START namelist input through fort.3. \&START contains a variety of variables related to the particular simulation being run and convergence parameters. The example fort. 3 file is listed below with the variables are listed and described in Table 13.

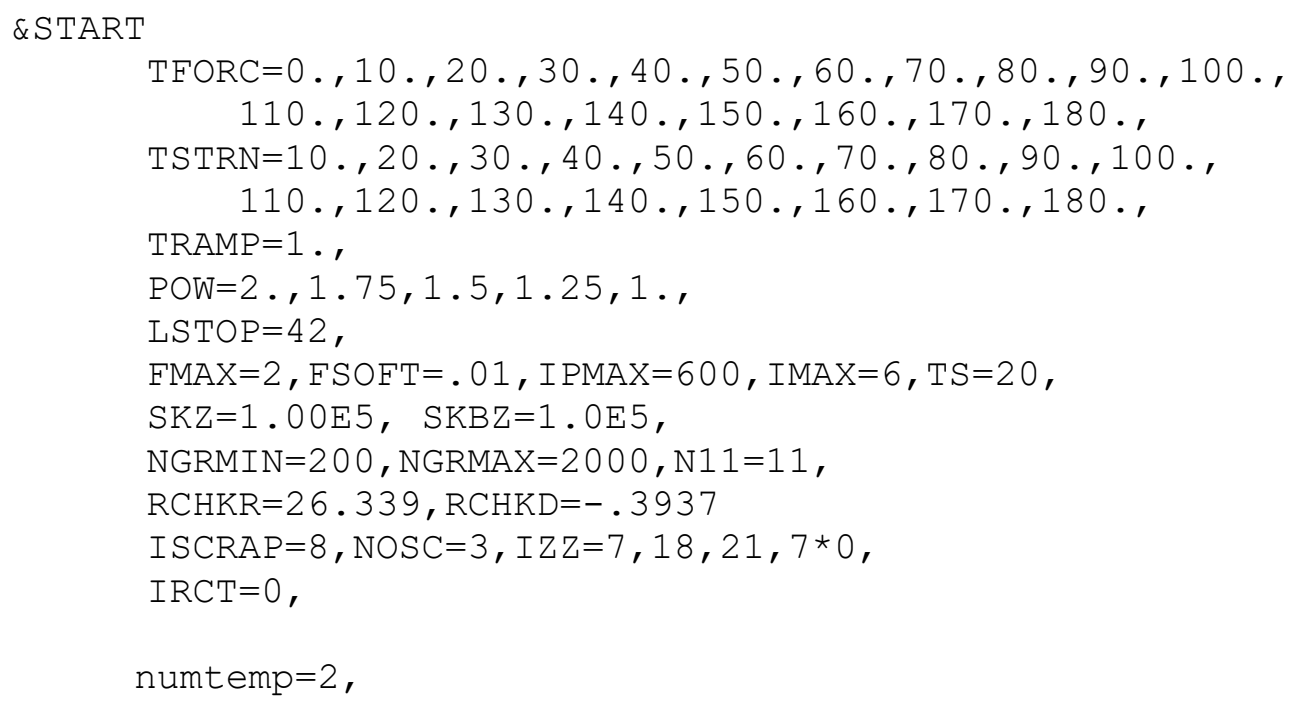


Supplement to the NUBOW-3D Manual

May 2015

$\mathrm{RTBL}=10 * 0$, table2=180,

$\& E N D$ 
Table 13 Variables for \&START namelist used in NUBOW 2

\begin{tabular}{|c|c|c|c|}
\hline $\begin{array}{l}\text { VARIABLE/ } \\
\text { DIMENSION }\end{array}$ & $\begin{array}{l}\text { DEFAULT/ } \\
\text { LIMIT }\end{array}$ & DESCRIPTION/FUNCTION & COMMENTS \\
\hline \multicolumn{4}{|c|}{ Restart Parameters } \\
\hline NSTART & 0 & Abnormal restart file number & Used to override the normal restart unit of 13 or 15. \\
\hline LSTART & 0 & Starting step in the current simulation & \\
\hline LSTOP & 430 & Final calculation step in the current simulation & Steps greater than LSTOP will not be calculated. \\
\hline TS & 12 & Iteration cutoff time for restart. & Not used in Windows implementation of NUBOW \\
\hline N1 & 13 & Input/Output File Number for System Data & $\begin{array}{l}\text { N1 is created by NB } 1 \text {; it contains geometric and force } \\
\text { data. NB } 2 \text { does not change this file but writes } \\
\text { changed data to N6 for restart. }\end{array}$ \\
\hline $\mathrm{N} 2$ & 20 & Input/Output File Number for System Data & $\begin{array}{l}\text { Data on this file remain constant during execution of } \\
\text { NB2 }\end{array}$ \\
\hline N3 & 26 & $\begin{array}{l}\text { Input/Output File Number for Cell Strains and } \\
\text { Fluences }\end{array}$ & Files N3 and N5 are used in a flip-flop manner \\
\hline N4 & 27 & $\begin{array}{l}\text { Input/Output File Number for Cell Geometry, Flux, \& } \\
\text { Temperature }\end{array}$ & Files N4 and N6 are used in a flip-flop manner \\
\hline N5 & 28 & $\begin{array}{l}\text { Input/Output File Number for Cell Strains and } \\
\text { Fluences }\end{array}$ & \\
\hline \multicolumn{4}{|c|}{ Calculation Steps } \\
\hline TFORCE (200) & 10000 & $\begin{array}{l}\text { Times, in reactor full power days, for calculating } \\
\text { equilibrium. }\end{array}$ & $\begin{array}{l}\text { Additional equilibrium calculations may be } \\
\text { introduced automatically as needed between strain } \\
\text { steps }\end{array}$ \\
\hline TSTRN (200) & 10000 & $\begin{array}{l}\text { Times, in reactor full power days, for calculating strain } \\
\text { increments due to creep and swelling. }\end{array}$ & $\begin{array}{l}\text { Additional strain calculations may be introduced by } \\
\text { automatically between equilibrium steps. Intervals } \\
\text { between strain steps should be sufficiently small to } \\
\text { maintain accuracy in the creep strain increment. } 10 \\
\text { days has been used but further study of this is } \\
\text { warranted. }\end{array}$ \\
\hline
\end{tabular}




\begin{tabular}{|c|c|c|c|}
\hline TRAMP (7) & 10000 & $\begin{array}{l}\text { Times, in reactor full power days, for calculating } \\
\text { thermal transients }\end{array}$ & $\begin{array}{l}\text { There appears to be a conflict between seven ramp } \\
\text { times and only six sets of POW and FLOW. This } \\
\text { needs investigation. } \\
\text { TRAMP times must b less than TSTRN, } \\
\text { TFORCE.Add a dummy step if TRAMP is needed at } \\
\text { the end of cycle. }\end{array}$ \\
\hline POW $(5,6)$ & 1 & $\begin{array}{l}\text { Reactor power (fraction of nominal full power). Five } \\
\text { power values for up to six thermal ramps }\end{array}$ & $\begin{array}{l}\text { Used in conjunction with FLOW to determine } \\
\text { temperatures and thermal bow shapes during thermal } \\
\text { transients. }\end{array}$ \\
\hline FLOW $(5,6)$ & 1 & $\begin{array}{l}\text { Coolant flow rate (fraction of full flow). Five flow } \\
\text { values for up to six thermal ramps. }\end{array}$ & $\begin{array}{l}\text { The only value used in the code is the power-to-flow } \\
\text { ratio POW/FLOW. }\end{array}$ \\
\hline TMIN & & $\begin{array}{l}\text { Initial time, in reactor full power days, for the current } \\
\text { simulation. }\end{array}$ & $\begin{array}{l}\text { Steps specified by TFORCE, TSTRN, or TRAMP at } \\
\text { times before TMIN will not be calculated. }\end{array}$ \\
\hline \multicolumn{4}{|c|}{ Convergence Parameters } \\
\hline FMAX & & Maximum allowed residual force for the stiff problem & $\begin{array}{l}\text { Traditionally, } 0.5 \mathrm{lbs} \text { has been used for most reactor } \\
\text { simulations. }\end{array}$ \\
\hline FSOFT & & $\begin{array}{l}\text { Maximum allowed residual force for the "soft" } \\
\text { problem. }\end{array}$ & $\begin{array}{l}\text { See page } 68 \text { of }[1] \text { for a discussion of the relationship } \\
\text { between FMAX, FSOFT, SKZ, and SKBZ. The } \\
\text { choices of these parameters are the "art" of getting } \\
\text { iterations to converge. }\end{array}$ \\
\hline SKZ & & Artificial contact stiffness used for the soft problem. & $\begin{array}{l}\text { Choose SKZ approximately equal to the softest load } \\
\text { pad contact stiffness }\end{array}$ \\
\hline SKBZ & & $\begin{array}{l}\text { Artificial beam bending stiffness used for the soft } \\
\text { problem. }\end{array}$ & $\begin{array}{l}\text { Choose approximately equal to the beam bending } \\
\text { stiffness at the ACLP }\end{array}$ \\
\hline IMAX & 5 & $\begin{array}{l}\text { Maximum number of iterations per "pass" to achieve } \\
\text { convergence of the soft problem. }\end{array}$ & $\begin{array}{l}\text { The three parameters IMAX, IPMAX, and NUM limit } \\
\text { the calculations spent in the three parts of the iteration } \\
\text { routine. }\end{array}$ \\
\hline IPMAX & 700 & Maximum number of "passes" for the soft problem & \\
\hline NUM & 1000000 & Iteration limit for the final stiff model & NUM was added to the \&START namelist in 2010 \\
\hline \multicolumn{4}{|c|}{$\begin{array}{r}\text { Reactivity Parameters } \\
\end{array}$} \\
\hline IRCT & 1 & $\begin{array}{l}\text { Indicator for method of treating reactivity. This may } \\
\text { not work properly for IRCT }<2 \text { in the current version } \\
\text { of the code. }\end{array}$ & $\begin{array}{l}\text { IRCT }>1 \text { requires reactivity data and fort. } 2 \text { input file } \\
\text { for IRCT }=1 \text {, set nReactsets }=0 \text { (fort. } 1 \text { ) }\end{array}$ \\
\hline
\end{tabular}




\begin{tabular}{|c|c|c|c|}
\hline RCHKR & 0 & $\begin{array}{l}\text { Core radius used for checking uniform dilation } \\
\text { reactivity change. }\end{array}$ & \\
\hline RCHKD & 0 & $\begin{array}{l}\text { Dilation used for checking uniform dilation reactivity } \\
\text { change. }\end{array}$ & \\
\hline NAREA & 0 & & \\
\hline NRWR11 & 2000 & & \\
\hline NW & 13 & & $\begin{array}{l}\text { This does not seem to be used in the current version of } \\
\text { NB2 }\end{array}$ \\
\hline $\mathrm{ZCB}$ & & axial position of the core bottom & Used for "chopped cosine" axial worth distribution \\
\hline $\mathrm{ZCC}$ & & axial location of the core center & $\begin{array}{l}\text { More documentation is required. These parameters } \\
\text { don't come into play if IRCT }=2\end{array}$ \\
\hline ZXTR & & Core extrapolation distance & \\
\hline JPRNT & 131 & & \\
\hline \multicolumn{4}{|c|}{ Graphics Output } \\
\hline NGRMIN & 200 & & \\
\hline NGRMAX & 200 & & \\
\hline N11 & 0 & file number for graphics data & \\
\hline ISCRAP & 0 & Number of ducts for limited displacement output & \\
\hline NOSC & & Number of nodes to output displacements for. & \\
\hline $\mathrm{IZZ}(10)$ & & Node numbers for selected output & \\
\hline \multicolumn{4}{|c|}{ Creep and Swelling } \\
\hline ABLG1 & & Duct pressure dilation compliance factor & See page 42 of [1] \\
\hline ABLG2 & & Duct contact force compliance factor & See page 42 of [1] \\
\hline TIMIN & -101 & & \\
\hline ISTRN & 1 & Strain calculation indicator & $\begin{array}{l}\text { ISTRN }=1 \text { will bypass creep and swelling strain } \\
\text { calculations }\end{array}$ \\
\hline
\end{tabular}




\section{Physics Input files}

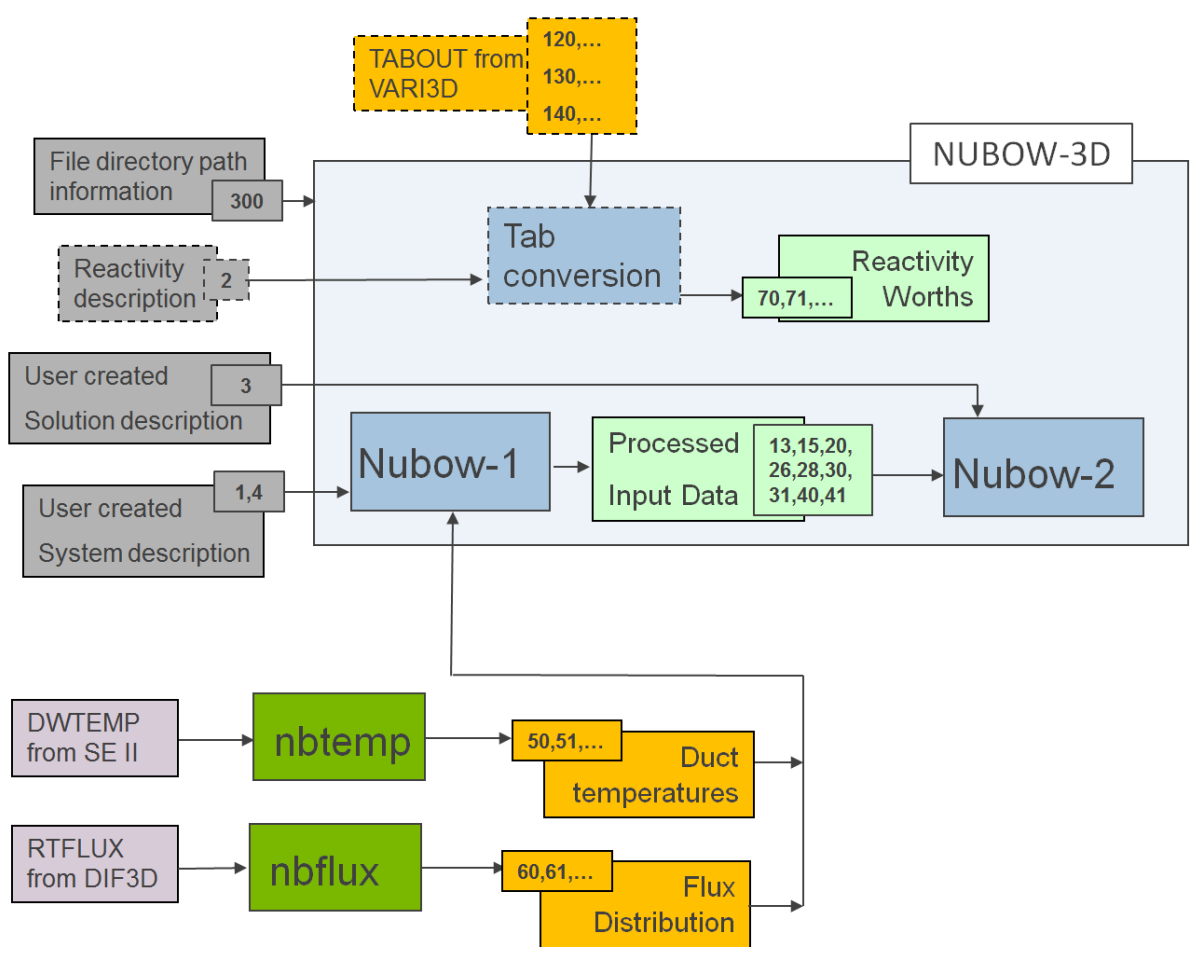

Figure 11 Phsyics Input files isolated in block diagram.

\subsection{Temperature input}
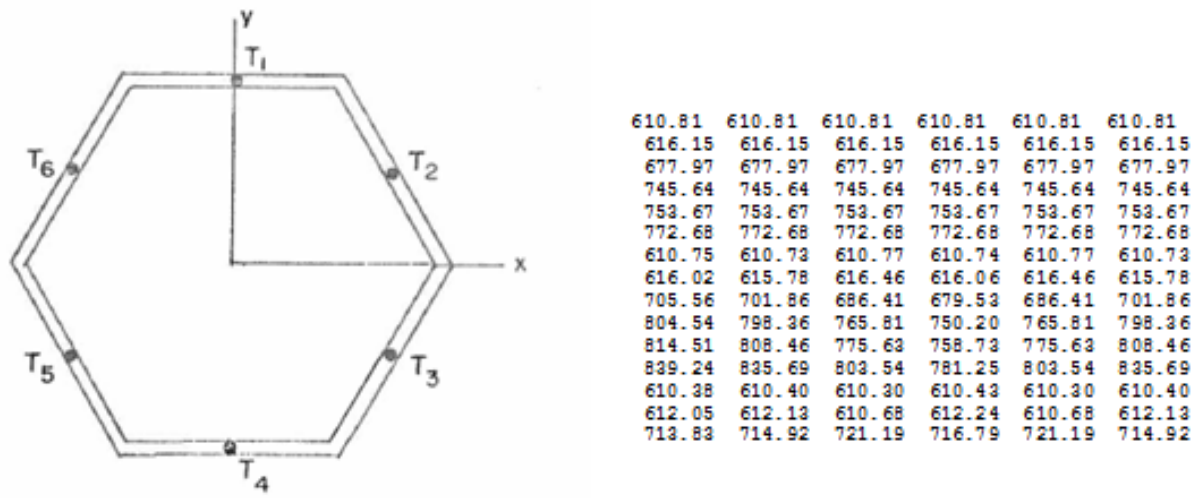

Figure 12 Face numbering convention in NUBOW for temperature input and sample data from formatted temperature input file.

The original version of the code allowed for a single temperature file over the duration of the core life cycle. The revision in 1987 created the ability to input up to 10 different temperature 
sets representing different times in the core life. NUBOW interpolates temperature between these points in time. At leas two temperature files should be used. The first set is read from unit 50 and the following sets follow incrementally on units $51,52, \ldots$ The files contain a temperature on each face for each temperature node. The temperature is uniform across duct face and is linearly interpolated at points along beam axis between thermal nodes.

The formatted files follow the form:

(face1,face 2 , face 3 , face 4 , face 5 ,face 6 , number of thermal nodes, duct number) Missing ducts are skipped in the file (see Figure 13).

\begin{tabular}{|c|c|c|c|c|c|c|}
\hline 806.47 & 842.99 & 913.34 & 989.77 & 913.34 & 842.99 & 13 \\
\hline 821.11 & 859.94 & 934.56 & 1010.78 & 934.56 & 859.94 & 13 \\
\hline 871.43 & 903.77 & 973.83 & 1029.66 & 973.83 & 903.77 & 13 \\
\hline 734.00 & 734.00 & 734.00 & 734.00 & 734.00 & 734.00 & 13 \\
\hline 736.19 & 736.19 & 736.18 & 736.27 & 736.27 & 736.18 & 13 \\
\hline 742.31 & 742.31 & 743.07 & 742.77 & 742.77 & 743.07 & 13 \\
\hline 752.01 & 752.01 & 753.99 & 753.16 & 753.16 & 753.99 & 13 \\
\hline 763.53 & 763.53 & 766.99 & 765.59 & 765.59 & 766.99 & 13 \\
\hline
\end{tabular}

Figure 13 Fort50 file illustrating the skipped missing duct number 10. 
NBTEMP

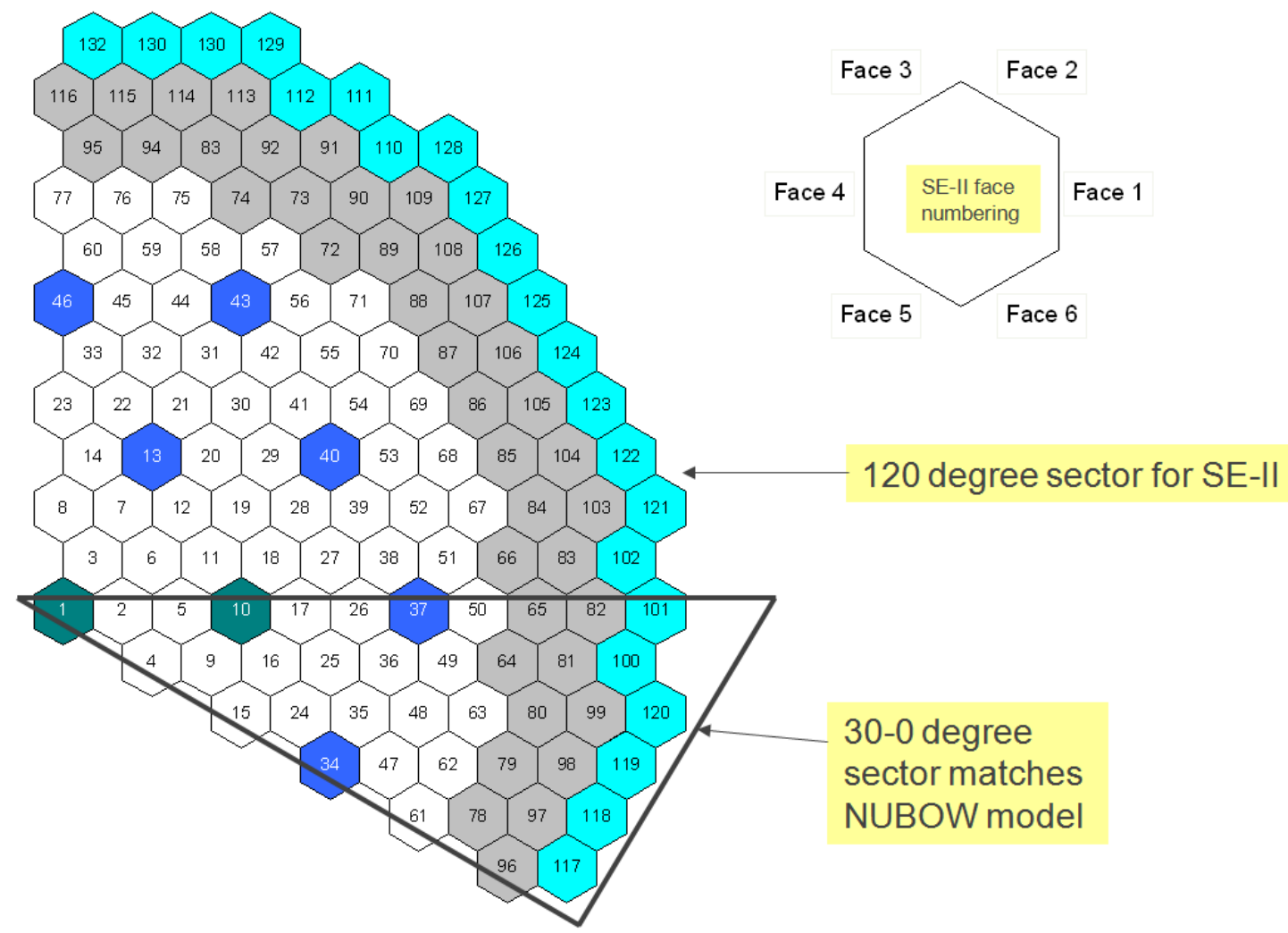

Figure 14 Comparison of the SE-II core description and the portion used for NUBOW

\subsubsection{NBTEMP}

NBTEMP is a NUBOW pre-processing code that converts temperature data calculated in the Super Energy II (SE-II) physics code. Be aware that in this section, the unit numbers are specific to the stand alone routine, NBTEMP with the exception of the output temperature files on units 50-59. The SE-II produces a temperature file called DWTEMP. The NBTEMP code converts this data into the temperature files that are input into Nubow-1. The codes main function is to translate between SE-II and NUBOW duct numbering conventions. The code produces the temperature files fort. 50,51, etc. depending on number of temperature sets read in (limit 10). NBTEMP is set-up to receive a binary temperature file. In the event that DWTEMP is provided as a text file, a program, BINFILE was created to convert this to the appropriate binary format. Both NBTEMP and BINFILE are packaged in a FOTRAN project called NBTEMP. The program takes as input, a namelist input file on UNIT1 and the text version of DWTEMP as unit 16. Table 14 lists the required input values. Two files are output from the NBTEMP file on the units defined by LOUT1 and LOUT2. The file defined by unit LOUT1 becomes the input files for the NUBOW run. The file needs to be converted to the corresponding unit 50-59 number corresponding to the temperature set that has been converted. For example, in the case where only BOC and EOC temperature sets are used, the BOC becomes unit 50 and the EOC becomes unit 51. These unit numbers are shown in 
Figure 5. The SE-II core description is a 120 deg core sector as shown in Figure 14. The text file of DWTEMP is actually from the SE2 output file.

\section{Obtain DWTEMP file}

2. Move a copy of the DWTEMP file and rename it to fort.16 and then into the directory where NBTEMP will execute it

3. Create a fort.1 file for NBTEMP

Table 14 INPUT namelist for NBTEMP

\begin{tabular}{|l|l|l|l|}
\hline Variable & $\begin{array}{l}\text { Max } \\
\text { value }\end{array}$ & $\begin{array}{l}\text { Normal } \\
\text { value }\end{array}$ & Description \\
\hline NROW & 20 & & $\begin{array}{l}\text { Largest number of rows in NUBOW 30-deg } \\
\text { sector. }\end{array}$ \\
\hline NODET & 25 & & $\begin{array}{l}\text { Number of axial locations for which temperature } \\
\text { is provide for NUBOW model. }\end{array}$ \\
\hline KNEED & 10 & & The selected SE-II axial locations. \\
\hline NOUT & & Number of ducts excluded in the core outer \\
rows.
\end{tabular}




\subsection{Neutron Flux input}

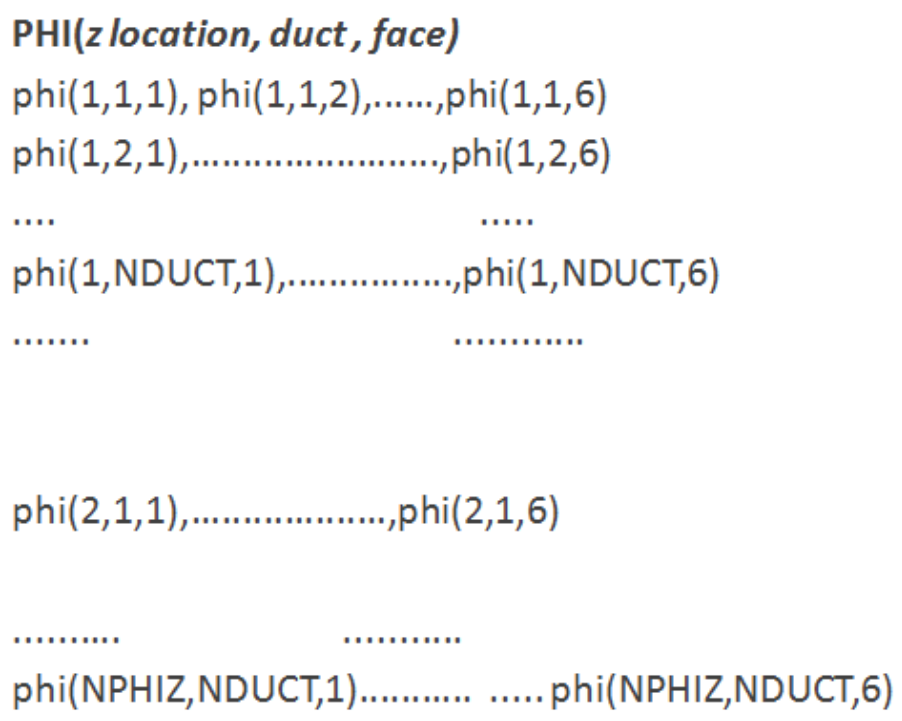

Figure 15 Format of flux file on UNIT 10.

Similar to the temperature files described above, NUBOW admits up to ten sets of flux files representing the flux at a given point in time. The neutron flux is read starting on unit 60 for the first time set and progressing incrementally through unit 69 if all ten sets are used. At least two sets should be used. The flux files (fort.60-69) contain flux data in 6 column rows where each row is faces 1-6 with NDUCT rows as shown in Figure 15. This is repeated for NPHIZ locations and contains NDUCT*NPHIZ rows. The rows are formatted as $6 \mathrm{E} 12.5$.

\subsubsection{NBFLUX}

NBFLUX is a NUBOW pre-processing code that converts neutron flux data calculated in the DIF-3D physics code. Be aware that in this section, the unit numbers are specific to the stand alone routine, NBFLUX with the exception of the output flux files on units 60-69. The DIF-3D code produces an output file called RTFLUX which is read in by NBFLUX. The NBFLUX code converts this data into the fort.10 file for NUBOW. The RTFLUX file needed for NUBOW should be produced with 6 triangular fluxes per hexagon. The RTFLUX file is a binary file and it is necessary to have the binary file created on the same hardware that is running NUBOW. A utility CDFILE can be used to convert the binary file into ASCII on the original machine that produced the RTFLUX file. Then, the ASCII file (renamed to RTFLUXC by CDFILE) can be ported to the machine running NUBOW and again using the CDFILE utility, converted back to a binary file.

The NBFLUX file reads an input namelist on unit 2. The variables are list in Table 1. The RTFLUX file nominally is on unit 12. The file designated by LOUT1 is the formatted flux data for NUBOW and should be renamed to fort.60-.61 corresponding to the flux set. 
Table 15 Variables for the NBFLUX INPUT namelist.

\begin{tabular}{|l|l|l|l|}
\hline Variable & $\begin{array}{l}\text { Max } \\
\text { value }\end{array}$ & $\begin{array}{l}\text { Normal } \\
\text { value }\end{array}$ & Description \\
\hline NROW & 20 & & $\begin{array}{l}\text { Largest number of rows in NUBOW 30-deg } \\
\text { sector. }\end{array}$ \\
\hline NPHIZ & 25 & & $\begin{array}{l}\text { Number of axial locations for which flux is } \\
\text { provided for the NUBOW model. }\end{array}$ \\
\hline KNEED & 30 & & DIF3D axial locations. \\
\hline NGMAX & & & $\begin{array}{l}\text { Number of energy groups that comprise the fast } \\
\text { flux. }\end{array}$ \\
\hline NOUT & 10 & & $\begin{array}{l}\text { Number of ducts excluded in the core outer } \\
\text { rows. }\end{array}$ \\
\hline JOUT & & & Ducts excluded in the core outer rows. \\
\hline LIN & & 10 & $\begin{array}{l}\text { Input file (RTFLUX) number. } \\
\text { (Used for NUBOW) }\end{array}$ \\
\hline LOUT1 & & 11 & Output file number for the 90-120 deg sector. \\
\hline LOUT2 & & \multicolumn{2}{|l}{}
\end{tabular}

\subsection{Optional Physics Input}

The reactivity calculation is an option. This feature is not described in this version of this document and this option is not used for the example problem provided within.

\section{Program execution}

The program starts by setting up a sequence of equilibrium and inelastic strain calculations to simulate power ramps and creep and swelling effects. It is necessary to follow each strain step with a new equilibrium calculation because the forces will relax after an inelastic strain interval. The program insures that this is done by inserting additional equilibrium steps where needed. It prints a calculation plan in the log file (fort.80). 
The three primary types of steps are: 1) strain steps in which the inelastic effects of irradiation creep and swelling are calculated over a time interval input by the user. 2) equilibrium steps in which the equilibrium position and the equilibrium contact forces for the current inelastic strain and thermal state. 3) Power ramps in which a series of equilibrium calculations are made for a scaled set of duct temperatures chosen to simulate the conditions of a reactor startup or shutdown. A fourth step is also available to use as a check of the reactivity "worth" values used in the code.

The equilibrium calculations begin by establishing the proper thermal conditions for the step including the thermal bow shapes, VTX, VTY, TVX, TVY, and the mean temperature of the load points as interpolated in time between temperature sets. The inelastic shapes are either zero, for a new step, or are available in VPX, VPY, etc. Next the clearances at load points, DEL are established. The equilibrium positions of the load points and the contact forces at those load points is determined through iteration to within a maximum force unbalance at any load point of FMAX pounds.

The inelastic strain step starts by establishing the elastic bow shape, and thus the stress state, at all the strain nodes followed by a calculation of inelastic strain effects for all beams for the time interval dtime. The system description following the strain calculation is written in the log file at the end of each strain step.

The power ramp steps begin by establishing the reactor power and the reactor coolant flow for the step and then proceeds directly into the equilibrium step calculations described above.

NUBOW uses a double iteration/relaxation method to solve the equilibrium equations describing the fast reactor core model. Gaps between load points introduce strong nonlinearities (local stiffness can vary by three to four orders of magnitude) which make the equations "stiff". Stiff equations are notoriously difficult to solve. NUBOW approaches this problem by first solving a series of relaxed problems in which the load pad stiffness is reduced to make the solution easier. After each relaxed solution is found by an iteration process, the solution is modified to correct local displacements to account for the softer load pad stiffness. When the corrections are sufficiently small, the approximate solution is used as a starting point for an iterative solution of the original stiff problem.

The clearances between load pads of adjacent assemblies and gaps at circular support points are calculated based on current inelastic strain and thermal effects. Thermal expansion of the ducts, grids, and restraint rings are included. Duct radii, i.e., the distance from the duct centerline to the hexagon face, are used in these calculations. Duct radii may change inelasticly. 


\section{References}

1. G. A. McLennan, Argonne National Laboratory, unpublished information, 1978.

2. MATLAB software, Mathworks, Natick, MA, USA 


\section{Appendices}

\subsection{Appendix A - Sample Input files}

\subsection{1 fort.1}

\&batchInput

sTitle=

'SMALL CORE SAMPLE PROBLEM; 25 DUCTS ',

$\mathrm{NODEG}=5 * 22$ ，

$\mathrm{ZG}=5 * 0 ., 5 * 9 ., 5 * 12.0,5 * 17.5,5 * 66.5,5 * 69 ., 5 * 71.5$,

$5 * 73.5,5 * 77.5,5 * 81.5,5 * 85.5,5 * 89.5,5 * 93.5,5 * 97.5$,

$5 * 101.5,5 * 105.5,5 * 107.5$,

$5 * 110 ., 5 * 112.5,5 * 171.5,5 * 174.5,5 * 179.5$,

\&end

'EOF'

\subsection{2 fort.4}

\section{$\&$ INPUT}

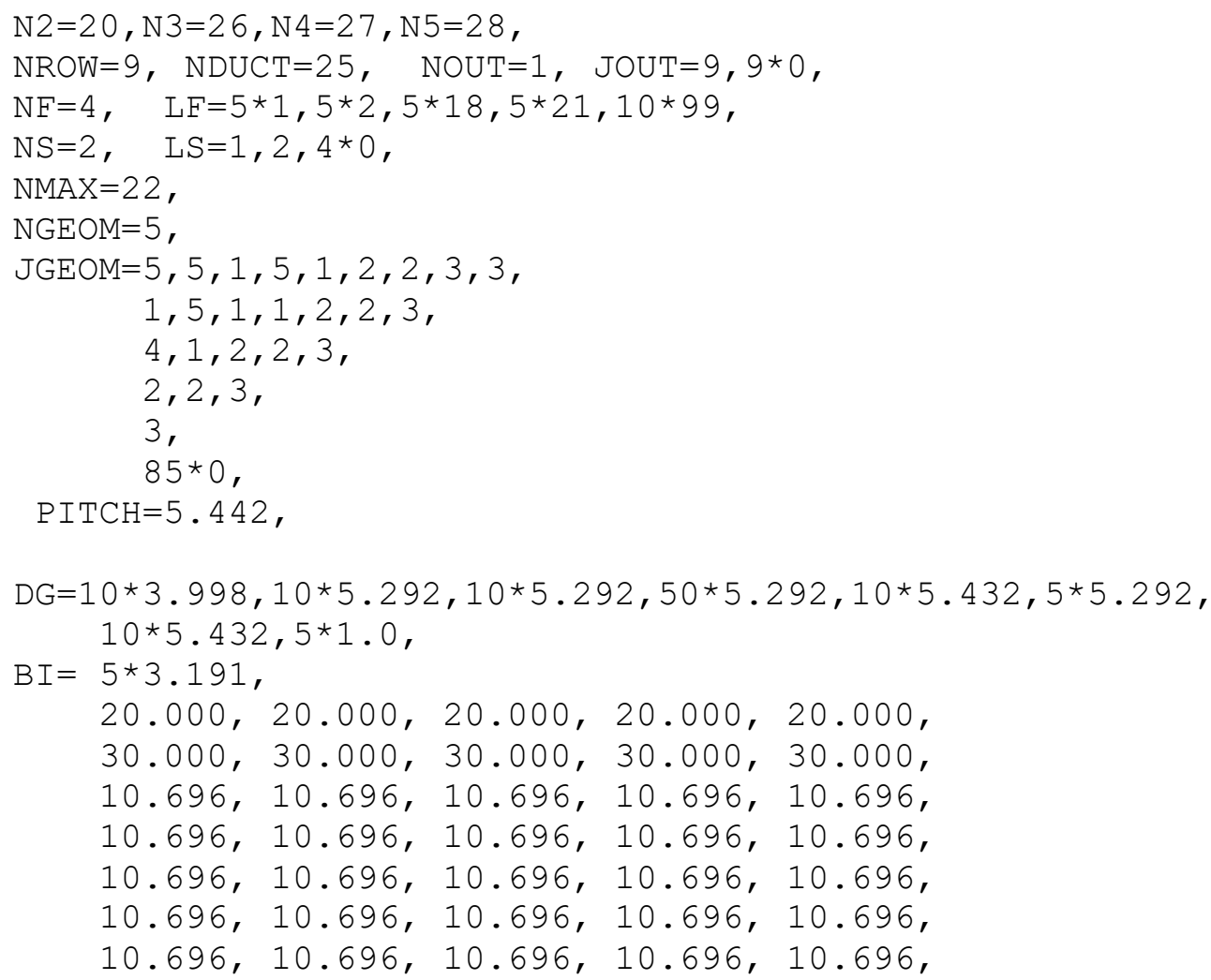




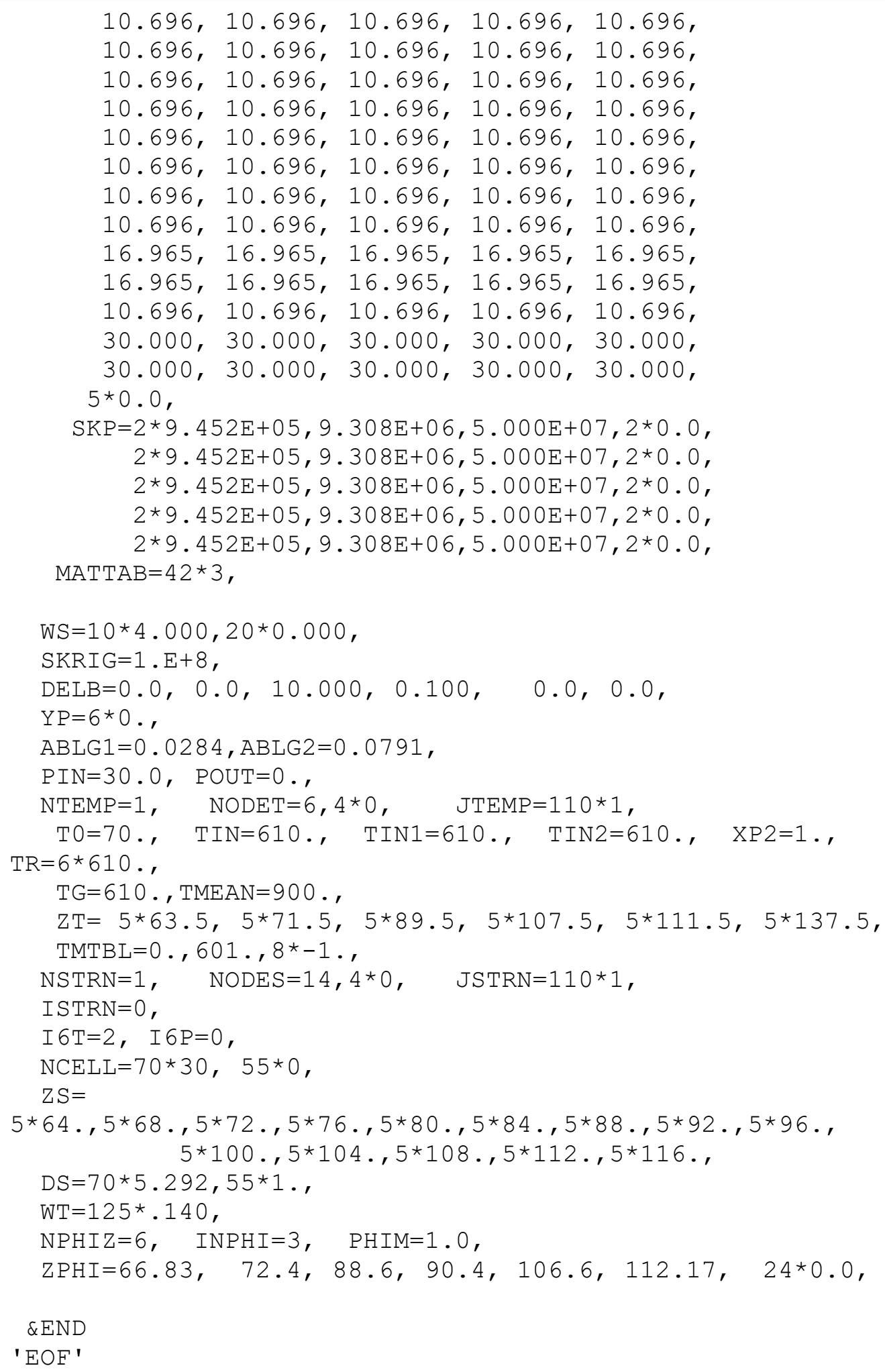

\subsection{3 fort.3}


$\&$ START

$\mathrm{TFORC}=0 ., 10 \ldots, 20 ., 30 ., 40 ., 50 ., 60 ., 70 \ldots, 80 ., 90 ., 100 \ldots$,

$110.120 .130 ., 140 ., 150 ., 160 ., 170 ., 180 \ldots$

$\operatorname{TSTRN}=10 ., 20 ., 30 ., 40 ., 50 ., 60 ., 70 ., 80 ., 90 ., 100 \ldots$, $110.120 .130 ., 140 ., 150 ., 160 ., 170 ., 180 .$,

$\mathrm{TRAMP}=1 \cdot$,

$\mathrm{POW}=2 ., 1.75,1.5,1.25,1 .$,

$\mathrm{LSTOP}=42$,

$\mathrm{FMAX}=2, \mathrm{FSOFT}=.01, \mathrm{IPMAX}=600, \mathrm{IMAX}=6, \mathrm{TS}=20$,

$\mathrm{SKZ}=1.00 \mathrm{E} 5, \mathrm{SKBZ}=1.0 \mathrm{E} 5$,

NGRMIN=200, NGRMAX $=2000, N 11=11$,

$\mathrm{RCHKR}=26.339, \mathrm{RCHKD}=-.3937$

$\mathrm{ISCRAP}=8, \mathrm{NOSC}=3, \mathrm{IZZ}=7,18,21,7 * 0$, $\mathrm{IRCT}=0$,

numtemp $=2$,

$\mathrm{RTBL}=10 * 0$,

table $2=180$,

$\& E N D$ 


\subsection{Appendix B - Core Geometry for verification problems}
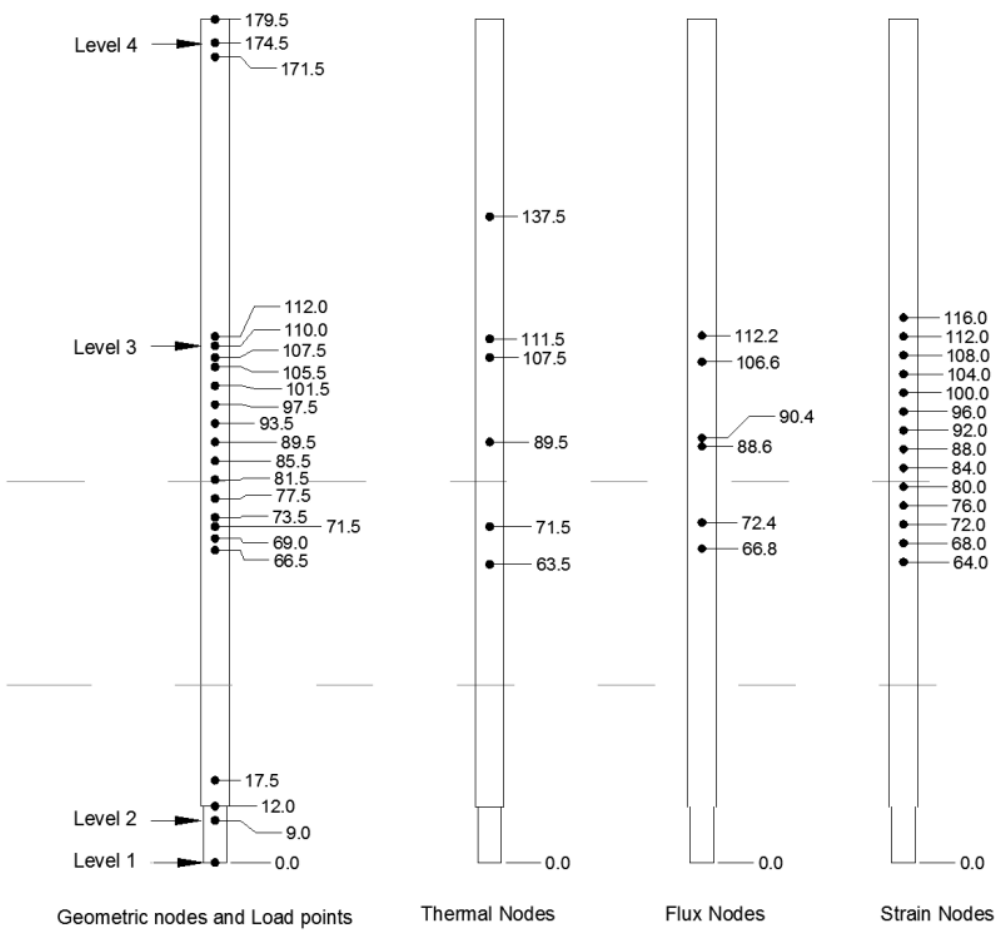

Figure 16 Node arrangement and location for load points for sample problem. Axial dimensions in inches.

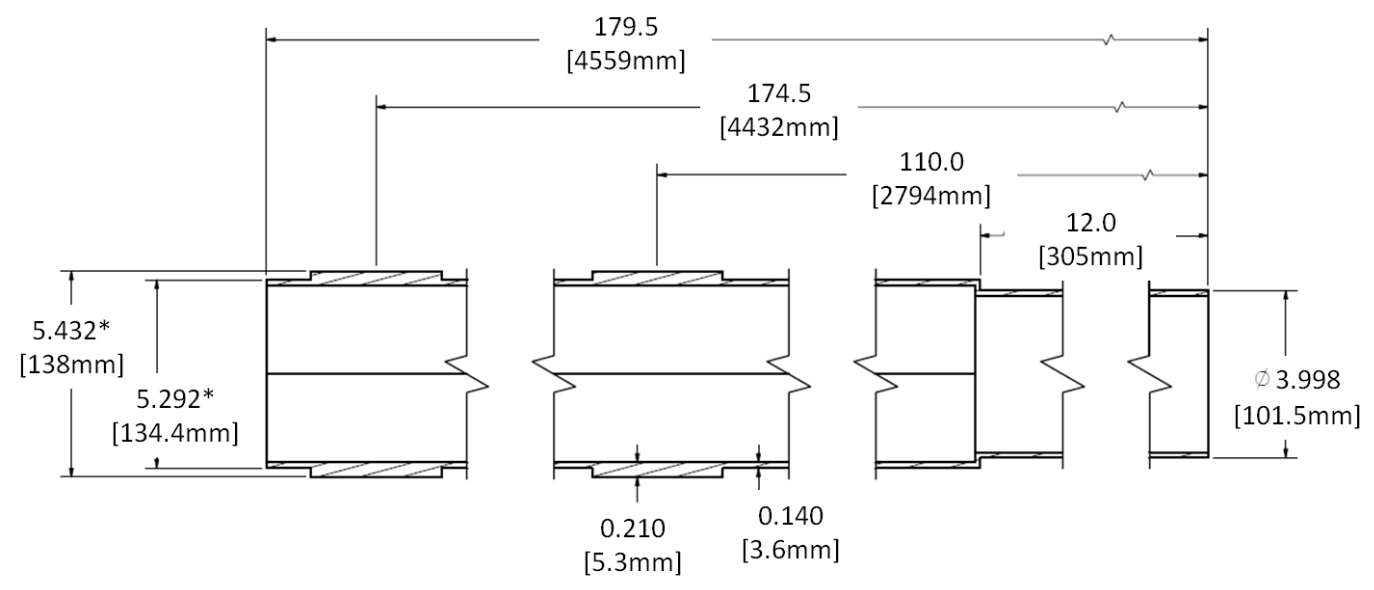

* Across the flats dimension

Figure 17 Duct dimensions for sample problem. Dimensions in inches/[mm]. 


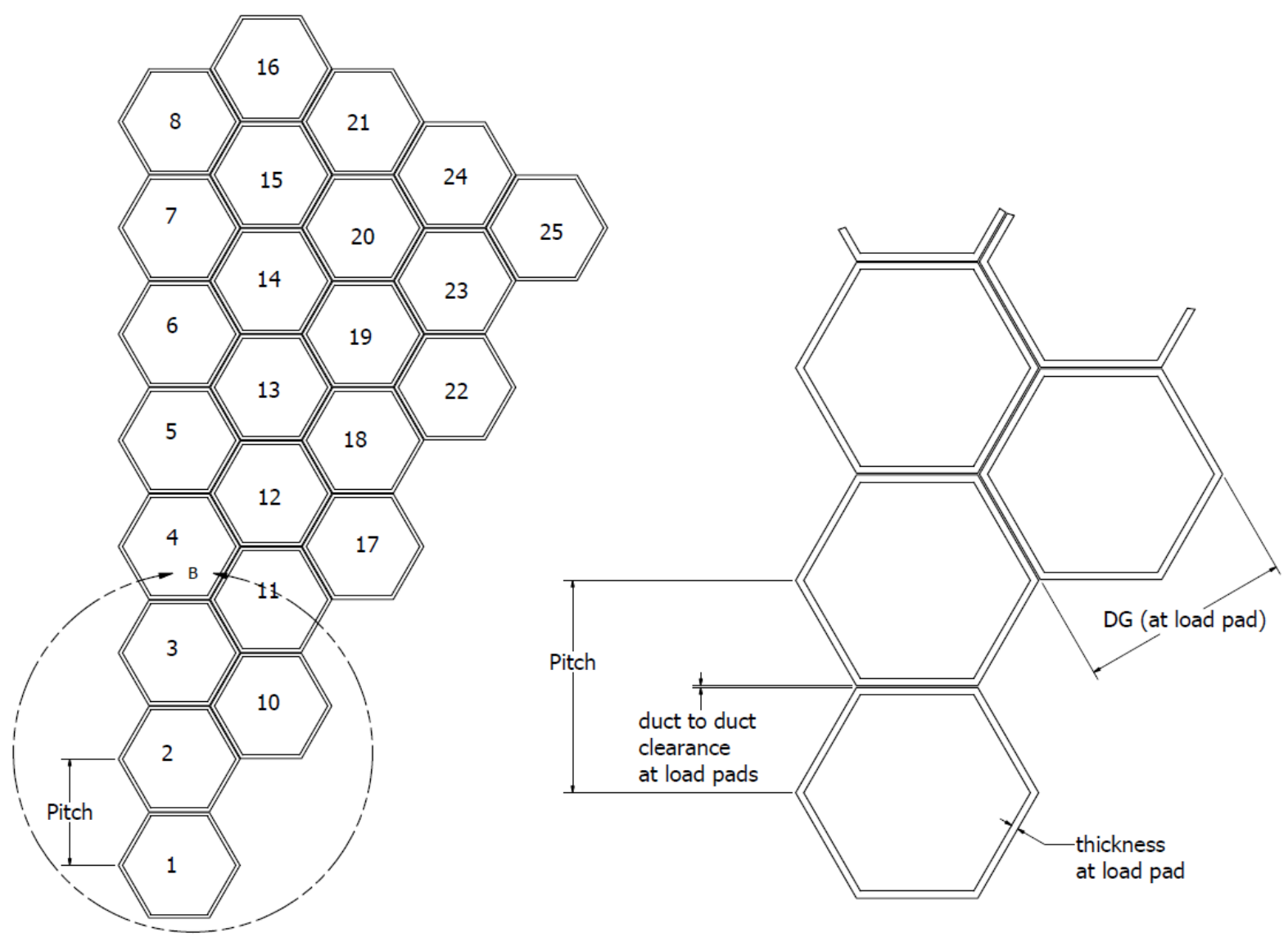

Figure 18 Schematic of core geometry 



\subsection{Appendix C- Running NUBOW-3D}

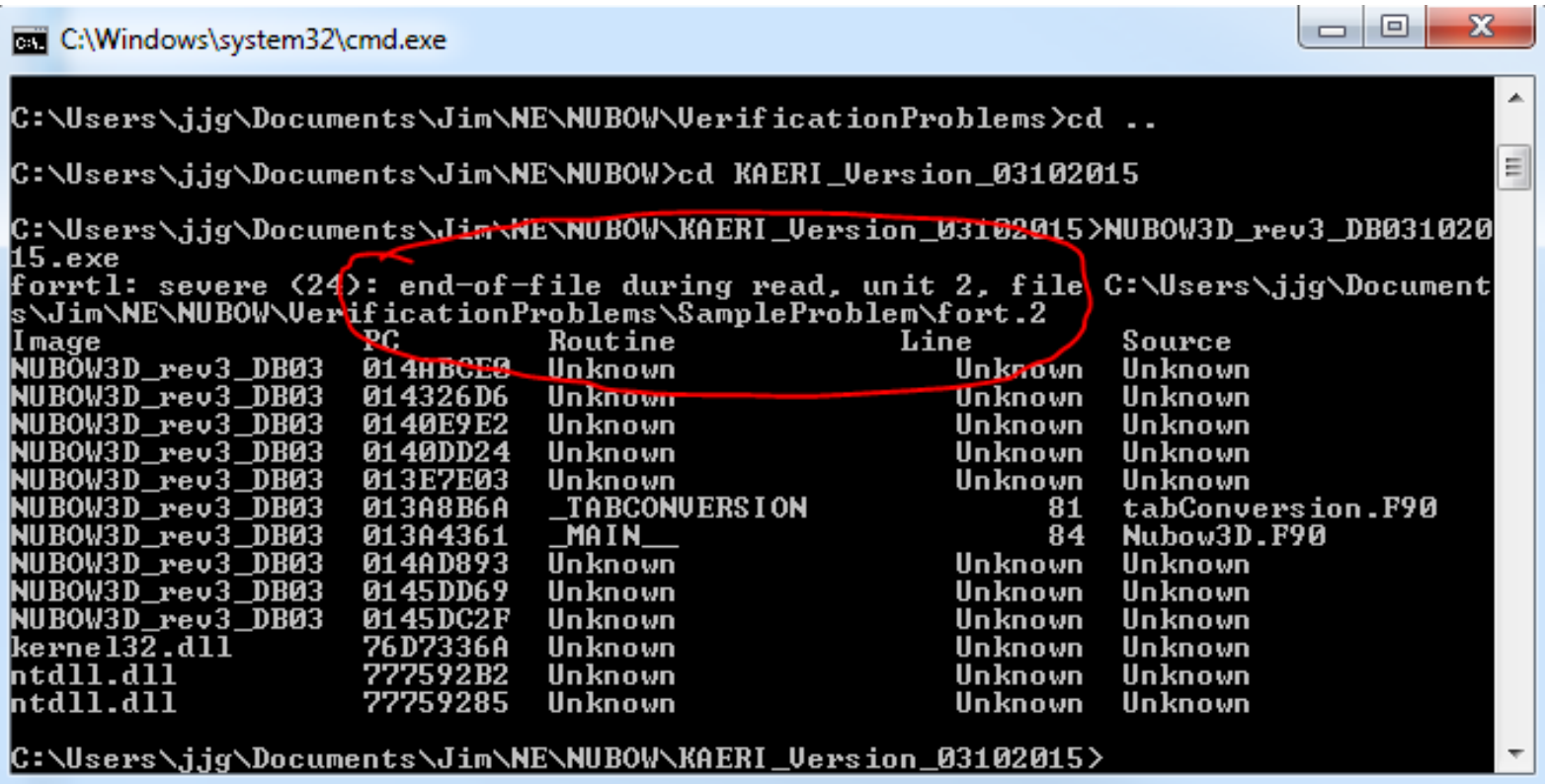

Figure 19 Running NUBOW from the command line provides information regarding input errors . 


\subsection{Appendix D-Detailed Explanation of Solution Process with reference to subroutines}

This repeats the material present in section 5 with additional detail regarding the internal code structure.

\subsubsection{Initialization}

The initial part of the program sets up various factors used in the calculation steps. These are:

Subroutine TRIGS fills the array TRIG with the components of unit vectors normal to the six hexagon faces. They are used by FORCES

Subroutine BASIS calculates radial position vector, RP, and radial unit vector, components EX and EY, for each assembly location in the array. It also calculates radial worth values, WJ, for each assembly based on row worth, WR.

Subroutine PRSUR determines duct internal pressure, PRES, at load points for each assembly. PRES is used by STRAIN to calculate duct dilation.

Subroutine BULGES has something to do with selecting nodes, LB and LFB, at which to calculate duct dilation (bulging) in STRAIN.

Subroutine STEPS sets up a sequence of equilibrium and inelastic strain calculations to simulate power ramps and creep and swelling effects. It is necessary to follow each strain step with a new equilibrium calculation because the forces will relax after an inelastic strain interval, STEPS insures that this is done by inserting additional equilibrium steps where needed. It prints a calculation plan.

\subsubsection{The Calculation Steps.}

The three primary types of steps are: 1) strain steps in which the inelastic effects of irradiation creep and swelling are calculated over a time interval input by the user. 2) equilibrium steps in which the equilibrium position and the equilibrium contact forces for the current inelastic strain and thermal state. 3) Power ramps in which a series of equilibrium calculations are made for a scaled set of duct temperatures chosen to simulate the conditions of a reactor startup or shutdown. A fourth step is also available to use as a check of the reactivity "worth" values used in the code.

Closing the step. After each step, a closing procedure is followed. NBPOST used a vector based graphics package, DISPLA, that is no longer available. The closing procedure is completed by writing a restart file, if needed, followed by a call to FBEAM to recalculate the elastic bow shapes at the end of the step and a call to REACT to perform a reactivity calculation for the step.

Equilibrium Calculations. The equilibrium calculations begin by establishing the proper thermal conditions for the step. Calls to Subroutine INTRP2 establish the thermal bow shapes, VTX, VTY, TVX, TVY, and the mean temperature of the load points, TAV based on the time of the step, TIME(L), and the temperatures in TABLE1 And TABLE2. The inelastic shapes are either zero, for a new step, or are available in VPX, VPY, etc. Next the clearances at load points, DEL are established by Subroutine BOUND. A time check is performed to verify that there is sufficient time to complete the next equilibrium calculation. A call to Subroutine ITER8 calculates the equilibrium positions of the load points and the contact forces at those load points 
to within a maximum force unbalance at any load point of FMAX pounds. The equilibrium step ends with the close out procedure described above.

Strain Calculations. After verifying that there is sufficient computer time to perform a strain calculation, the inelastic strain step starts with a call to Subroutine FBEAM to establish the elastic bow shape, and thus the stress state, at all the strain nodes. Then, a call to Subroutine INELAS calculates inelastic strain effects for all beams for the time interval dtime. Strain data are read and updated using units 26 and 28 in a flip/flop fashion. A system description following the strain calculation is printed using Subroutine WRTR, then followed by the close out procedure.

Power Ramps. The power ramp steps begin by establishing the reactor power, POW0 and the reactor coolant flow, FLOW0, for the step and then proceeds directly into the equilibrium step calculations described above including the close out procedure.

Uniform radial dilation checks are performed by a call to Subroutine REXP followed by a zeroing of the inelastic bow shapes at strain nodes, PVX and PVY. The step ends with the close out procedure.

\subsubsection{Equilibrium step calculations}

Subroutine ITER8 uses a double iteration/relaxation method to solve the equilibrium equations describing the NUBOW3D model of a fast reactor core. These equations involve about 252 independent variables, i.e., load point displacements, for a $30^{\circ}$ symetric sector of a twelve row reactor. Gaps between load points introduce strong nonlinearities (local stiffness can vary by three to four orders of magnitude) which make the equations "stiff". Stiff equations are notoriously difficult to solve. NUBOW approaches this problem by first solving a series of relaxed problems in which the load pad stiffness is reduced to make the solution easier. After each relaxed solution is found by an iteration process, the solution is modified to correct local displacements to account for the softer load pad stiffness. When the corrections are sufficiently small, the approximate solution is used as a starting point for an iterative solution of the original stiff problem.

Subroutine BOUND calculates clearances between load pads of adjacent assemblies and gaps at circular support points based on current inelastic strain and thermal effects. Thermal expansion of the ducts, grids, and restraint rings are included. Duct radii, i.e., the distance from the duct centerline to the hexagon face, are used in these calculations. Duct radii may change inelasticly; Subroutine STRAIN calculates duct radii.

Subroutine TFACS generates temperature scale factors, PFR \& YF, used in TFUNC for linear interpolation of temperatures during power ramps

\subsubsection{The NB2 iteration scheme}

Subroutine ITRE8 is used to calculate the equilibrium positions and forces for a given state of thermal and inelastic bow of the reactor assemblies. It begins with some preliminary housekeeping setting the variables FSFT, FMX10, M1, BETA1, BETA@, NR11, NQ11 and writing to the __ file. Next it zeros out the load point position arrays VX and VY, the load point ___ variables UX and UY, the___ array DB, and the shim array DS if the run is not a restart of an unfinished equilibrium calculation. It then sets ISAVE and JSAVE to 1, Calculates the inverse stiffness matrix for each assembly type, and saves the computer job time TSAVE. 
The inner iteration scheme is an iteration of load point positions, VX and VY, to achieve equilibrium for a given state of system stiffness and shimming. It uses NIT as an iteration counter and FT as a cutoff limit. . When the maximum load point residual, FMAX, is less than FT, that loop is deemed converged. The inner loop ends when it is converged or the number of iterations exceeds the maximum of 99999 iterations.

The outer iteration scheme is a series of "shimming" procedures in which shims, DS, are added after each successive inner equilibrium calculation. Shimming accounts for the excessive relative displacement between two adjacent assemblies induced by the softer contact stiffness. IPASS is the counter used for the shimming iterations; it has a cutoff maximum of IPASS. When the two variables, ISTOP and IRIG, control how the logic flows. For a normal start of a new equilibrium calculation, ISTOP and IRIG are both 0 . IRIG controls whether or not a shimming calculation is done. For IRIG $=0$, Shims are calculated after the completion of a "pass". ISTOP $=0$ indicates the iterations are using the "soft" contact stiffness and bending stiffness as given by the input variables SKZ and SKBZ in conjunction with shims. ISTOP = 1 indicates the model is using the hard stiffness, SKP, with the correct bending stiffness, ---, and no shims. Two events trigger a change of ISTOP to 1 . If the number of iterations needed to complete the inner loop and the shimming is $\leq 2$, IRIG is set to 1 and flow returns to line 10 . Then ISTOP is set to 1 . Second, if the remaining time on the computer job at the start of an iteration is too short ISTOP is set to 1 and the program exits. Third, if the number of iterations is $\geq 1000000$, and IRIG is 1 and ISTOP is 0 , ISTOP is set to 1 .

\author{
ISTOP $=1$ : Normal stiffness \\ IRIG=1 : No shims
}




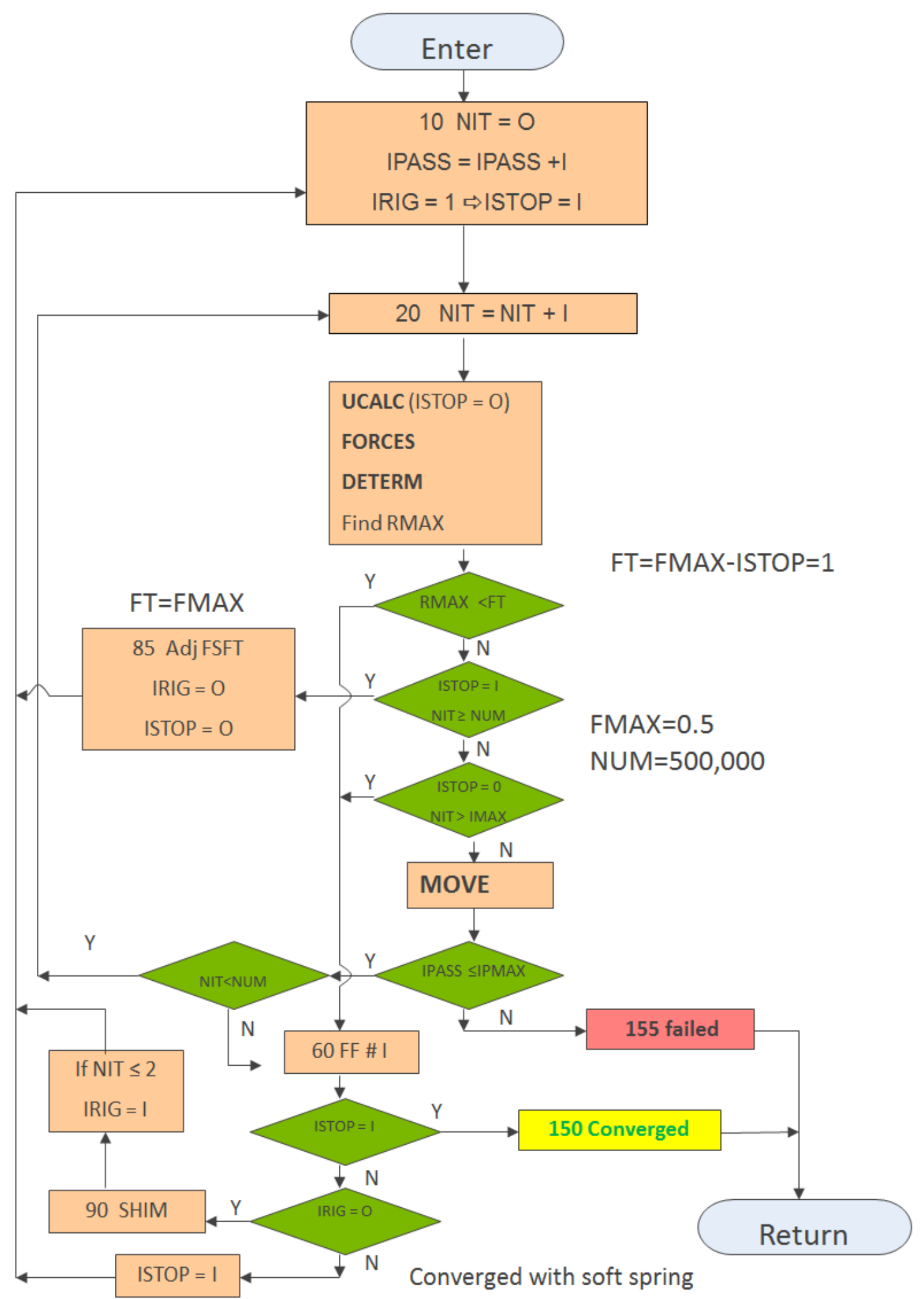

Figure 20 Flow chart of iteration sub-routine ITER8 


\subsubsection{Strain step calculations}

Subroutine INELAS calculates inelastic strain effects for all beams for the time interval dtime. strain data are read and updated using units 26 and 28 in flip/flop fashion.

First, a call to Subroutine MOMENT calculates $\mathrm{x}$ and $\mathrm{y}$ bending moments at strain nodes due to beam forces. With the shear force and bending moment known, the stress in each strain cell is known based on beam theory. Then a call Subroutine STRAIN reads current strains and fluence from unit $\mathrm{n} 3$, increments them over a time step, DTIME, based on the temperature and flux state at the middle of the time step, and writes the incremented values on unit $\mathrm{n} 5$. This routine also calculates new curvatures at strain nodes.

Within Subroutine STRAIN, Subroutine CSLAWA provides irradiation creep and swelling correlations for AISI 316, D-9 and HT-9. Functions YOUNG and TXP give temperature dependant Young's Modulus and thermal expansion coefficients for those materials,

Subroutine BOWSVE then copies VP for one duct to save it in VPS. Next Subroutine BOW2 calculates free bow shapes from given values of curvature. the curvature is known at nodes, and the bow shape is calculated at nodeg. the logic assumes a linear variation in curv between each nodes, at axial positions ZS. bowed shapes at nodes are calculated from the given curvatures and the interpolated/extrapolated to give bow shapes at NODEG, at axial positions ZG. 


\subsection{Appendix E - identification of key variables in NUBOW 2 program}

\begin{tabular}{|c|c|c|c|}
\hline Variable & Dimensions & Description & Comment \\
\hline A & $(6,6,5)$ & Flexibility matrix for Assembly & $\begin{array}{l}{\left[\mathrm{K}+\mathrm{k}_{\mathrm{b}}\right]^{-1} \text { in Eqn. } 58 \text { of }} \\
{[1] ; \text { Calculated in DMINV }}\end{array}$ \\
\hline$\overline{\mathrm{DB}}$ & $(\mathrm{N}, \mathrm{M}, 2)$ & $\begin{array}{l}\text { Bending displacement based on } \\
\text { artificial bending stiffness SKBZ }\end{array}$ & $\begin{array}{l}\text { See lines } 1417 \text { to } 1418 \text { of } \\
\text { NUBOW-2 }\end{array}$ \\
\hline DEL & $(\mathrm{N}, \mathrm{M}, 6)$ & $\begin{array}{l}\text { Gap at a load point including } \\
\text { thermal and inelastic effects. }\end{array}$ & $\begin{array}{l}\text { See } \delta_{\mathrm{i}} \text { in Eqn. (61) of [1]. } \\
\text { Calculated in BOUND }\end{array}$ \\
\hline DS & $(\mathrm{N}, \mathrm{M}, 6)$ & Shims for soft contact forces & See $S_{i}$ in Eqn. 67 of [1]. \\
\hline FB & $(\mathrm{N}, \mathrm{M}, 2)$ & $\begin{array}{l}\text { Assembly shear force due to } \\
\text { constrained deflection }\end{array}$ & See $F_{B}$ in Eqn. 54. of [1] \\
\hline FF & $(\mathrm{N}, \mathrm{M}, 6)$ & Contact forces at a load point & See $F_{c}$ in Eqn. (53) of [1] \\
\hline FMAX & & $\begin{array}{l}\text { Maximum allowed residual for } \\
\text { convergence }\end{array}$ & Used for IRIG $=1$ \\
\hline FSOFT & & $\begin{array}{l}\text { Force convergence criteria for } \\
\text { "soft" system }\end{array}$ & $\begin{array}{l}\text { See p. } 68 \text { of [1] for a } \\
\text { discussion of these } \\
\text { variables. Used when } \\
\text { IRIG }=0\end{array}$ \\
\hline IMAX & 5 & $\begin{array}{l}\text { Limit to number of iterations for } \\
\text { the soft model. }\end{array}$ & Used when ISTOP $=0$ \\
\hline IPMAX & 700 & $\begin{array}{l}\text { Limit to number of "passes" for } \\
\text { soft model. }\end{array}$ & Used when ISTOP $=0$ \\
\hline ISAVE & & $\begin{array}{l}\text { Load level of the maximum } \\
\text { residual }\end{array}$ & \\
\hline ISTEP & & $\begin{array}{l}\text { 1: Strain } \\
\text { 2: Equilibrium } \\
\text { 3: Dilation } \\
>3: \text { Ramp }[11,21,31,41,51] \\
\text { [ramp step, ramp sequence] }\end{array}$ & \\
\hline ISYM & & Symmetry indicator & $\begin{array}{l}\text { ISYM }<1 \text { indicates no } \\
\text { assumed symmetry }\end{array}$ \\
\hline JOUT & (10) & $\begin{array}{l}\text { Assembly numbers of the missing } \\
\text { assemblies }\end{array}$ & \\
\hline JAD & $(6, \mathrm{M})$ & $\begin{array}{l}\text { Address of six adjacent } \\
\text { assemblies }\end{array}$ & \\
\hline JGEOM & $(M)$ & Geometric type of assembly & \\
\hline JSAVE & & $\begin{array}{l}\text { Assembly number of the } \\
\text { maximum residual }\end{array}$ & \\
\hline JSTRN & $(M)$ & Strain type of assembly & \\
\hline JTEMP & $(M)$ & Thermal type of assembly & \\
\hline KFLAG & & Vector of types by step & \\
\hline KSAVE & & $\begin{array}{l}\text { Direction of the maximum } \\
\text { residual }\end{array}$ & $1=X, 2=Y$ \\
\hline $\mathrm{L}$ & & current step & \\
\hline
\end{tabular}




\begin{tabular}{|c|c|c|c|}
\hline Variable & Dimensions & Description & Comment \\
\hline L1 & & $\begin{array}{l}\text { first step. } \\
0: \text { new } \\
\text { ? : restart } \\
\end{array}$ & \\
\hline $\mathrm{LF}$ & $(5,6)$ & & \\
\hline LS & & $\begin{array}{l}\text { Load point number of a support } \\
\text { point }\end{array}$ & \\
\hline M & & Number of assemblies/ducts & \\
\hline M1 & & $\begin{array}{l}\text { First assembly with allowed } \\
\text { displacements }\end{array}$ & $\begin{array}{l}\text { M1 }=2 \text { for } 30^{\circ} \text { symmetric } \\
\text { sector }\end{array}$ \\
\hline $\mathrm{N}$ & & Number of load points & \\
\hline NODEG & $(M)$ & Number of geometric nodes & \\
\hline NODET & $(M)$ & Number of thermal nodes & \\
\hline NODES & $(M)$ & Number of strain nodes & \\
\hline NOUT & & $\begin{array}{l}\text { Number of assemblies missing } \\
\text { from the array }\end{array}$ & \\
\hline NS & & Number of support points & \\
\hline NSTEP & & Number of steps to be calculated & \\
\hline NUM & 1000000 & $\begin{array}{l}\text { Limit to the number of iterations } \\
\text { for the rigid model }\end{array}$ & Used for ISTOP $=1$ \\
\hline PVX & & \multirow{2}{*}{ Inelastic deflection at all ZG } & \\
\hline PVY & & & \\
\hline $\mathrm{R}$ & $(\mathrm{N}, \mathrm{M}, 2)$ & & \\
\hline RD & $\begin{array}{l}\text { (support } \\
\text { point, duct, } \\
\text { face) }\end{array}$ & & \\
\hline RMAX & & $\begin{array}{l}\text { Maximum residual at current } \\
\text { iteration }\end{array}$ & $\begin{array}{l}\text { RMAX may be either an } \\
X \text { or } Y \text { component of } R\end{array}$ \\
\hline SK & $(\mathrm{N}, \mathrm{M}, 6)$ & $\begin{array}{l}\text { Assembly bending stiffness } \\
\text { matrix }\end{array}$ & See $\left[\mathrm{k}_{\mathrm{b}}\right]$ in Eqn. (53) of [1] \\
\hline SKB & $(6,6,5)$ & $\begin{array}{l}\text { Contact stiffness at load points for } \\
\text { each geometric type }\end{array}$ & Used when IRIG $=1$ \\
\hline SKZ & & $\begin{array}{l}\text { Artificial contact stiffness used } \\
\text { for soft contacts }\end{array}$ & Used when IRIG $=0$ \\
\hline SKBZ & & Artificial beam stiffness & Used when IRIG $=0$ \\
\hline TAV & & $\begin{array}{l}\text { Average nodal temperature at } \\
\text { load point }\end{array}$ & \\
\hline TIME(L) & & Time in days & \\
\hline TRIG & $(2,6)$ & Trigonometric quantities & See [1], Eqn. (59)-(60) \\
\hline TVX & & \multirow{2}{*}{ Thermal deflection at all ZG } & \\
\hline TVY & & & \\
\hline $\mathrm{UX}$ & $(\mathrm{N}, \mathrm{M})$ & $\begin{array}{l}\text { Elastic load point displacement in } \\
\text { the X direction }\end{array}$ & \multirow{2}{*}{$\begin{array}{l}\mathrm{UX} \text { and } \mathrm{UY} \text { are the } \\
\text { components of } \mathrm{v}_{\mathrm{e}} \text { in Eqn. } \\
\text { (58) of [1] }\end{array}$} \\
\hline UY & $(\mathrm{N}, \mathrm{M})$ & $\begin{array}{l}\text { Elastic load point displacement in } \\
\text { the Y direction }\end{array}$ & \\
\hline
\end{tabular}




\begin{tabular}{|c|c|c|c|}
\hline Variable & Dimensions & Description & Comment \\
\hline VPX & $(\mathrm{N}, \mathrm{M})$ & $\begin{array}{l}\text { X plastic displacement of a load } \\
\text { point }\end{array}$ & \multirow{4}{*}{$\begin{array}{l}\text { VTX, VTY, VPX, and } \\
\text { VPY are the components } \\
\text { of VB in Eqn. (54) of [1] }\end{array}$} \\
\hline VPY & $(\mathrm{N}, \mathrm{M})$ & $\begin{array}{l}\text { Y plastic displacement of a load } \\
\text { point }\end{array}$ & \\
\hline VTX & $(\mathrm{N}, \mathrm{M})$ & $\begin{array}{l}X \text { thermal displacement of a load } \\
\text { point }\end{array}$ & \\
\hline VTY & $(\mathrm{N}, \mathrm{M})$ & $\begin{array}{l}Y \text { thermal displacement of a load } \\
\text { point }\end{array}$ & \\
\hline $\mathrm{VX}$ & $(\mathrm{N}, \mathrm{M})$ & $\begin{array}{l}\mathrm{X} \text { total displacement of a load } \\
\text { point }\end{array}$ & $\begin{array}{l}\text { VX and VY are the X and } \\
\text { Y components of } v \text { in Eqn. } \\
\text { (54) of [1] }\end{array}$ \\
\hline VY & $(\mathrm{N}, \mathrm{M})$ & $\begin{array}{l}\text { Y total displacement of a load } \\
\text { point }\end{array}$ & \\
\hline
\end{tabular}




\subsection{Appendix G - NB1 Subroutines}

\begin{tabular}{|l|l|l|}
\hline SUBROUTINE & Description & Comments \\
\hline RADII & $\begin{array}{l}\text { Fills array RD(support point,duct,face) } \\
\text { at load points }\end{array}$ & \\
\hline WRIT1 & writes to files 13,20 & \\
\hline & & \\
\hline & & \\
\hline & & \\
\hline & & \\
\hline & & \\
\hline
\end{tabular}




\subsection{Appendix H - NB2 Subroutines}

\begin{tabular}{|c|c|c|}
\hline SUBROUTINE & Description & \\
\hline WRTR & $\begin{array}{l}\text { Writes system description, bowed } \\
\text { shapes and duct clearances }\end{array}$ & \\
\hline ITER8 & Solution iteration routine & $\begin{array}{l}\text { outputs forces, VX,VY, } \\
\text { and RX,RY }\end{array}$ \\
\hline BASIS & $\begin{array}{l}\text { Calculates radial unit vectors and the } \\
\text { radial position of each duct in a } 30 \\
\text { deg. Sector. The unit vectors are given } \\
\text { in } x \text { and y components as EX(j) and } \\
E Y(j) \text { for each duct } j \text {. The radial } \\
\text { positions are RP(j). Also, the worth } \\
\text { values for all ducts are calculated from } \\
\text { row values. Worths for duct } 1 \text {, and } \\
\text { those deleted as JOUT are set to } 0 .\end{array}$ & \\
\hline BOUND & $\begin{array}{l}\text { Calculates clearance gaps for all } \\
\text { contact points. These include each of } \\
\text { six faces for hex load pads, and gaps } \\
\text { at circular supports. Thermal } \\
\text { expansion of the ducts, grids, and } \\
\text { restraint rings are included. Duct radii } \\
\text { are used, which may change } \\
\text { inelastically. These inelastic changes } \\
\text { are calculated in subr. Strain. }\end{array}$ & \\
\hline BOW2 & $\begin{array}{l}\text { Calculates free bow shapes from given } \\
\text { values of curvature. The curvature is } \\
\text { known at nodes, and the bow shape } \\
\text { is calculated at NODEG. The logic } \\
\text { assumes a linear variation in curv } \\
\text { between each nodes, at axial } \\
\text { positions ZS. Bowed shapes at nodes } \\
\text { are calculated from the given } \\
\text { curvatures and the } \\
\text { interpolated/extrapolated to give bow } \\
\text { shapes at NODEG, at axial positions } \\
\text { ZG. }\end{array}$ & \\
\hline READER & Reads input files N1, N2 & \\
\hline STEPS & $\begin{array}{l}\text { Determines the calculation steps } \\
\text { specified and required for problem run. }\end{array}$ & \\
\hline WRITER & Writes to N1 & \\
\hline CSLAWA & $\begin{array}{l}\text { Creep and swelling rate } \\
\text { correlations/calc. }\end{array}$ & \\
\hline
\end{tabular}




\begin{tabular}{|l|l|l|}
\hline IDET & $\begin{array}{l}\text { Appears to check to see if duct is } \\
\text { determinate or not by comparing } \\
\text { current forces to a min. force value, } \\
\text { (local) FMIN which is set to 0.0001 in } \\
\text { the subroutine. }\end{array}$ & \\
\hline & & \\
\hline
\end{tabular}




\section{Argonne}

Nuclear Engineering Division

Argonne National Laboratory

9700 South Cass Avenue, Bldg. 208

Lemont, IL 60439

www.anl.gov 